\title{
A comparative study on the cyclic plasticity and fatigue failure behavior of different subzones in CrNiMoV steel welded joint
}

\author{
Su-Juan Guo ${ }^{\mathrm{a}}$, Run-Zi Wang ${ }^{\mathrm{a}}$, Haofeng Chen ${ }^{\mathrm{a}, \mathrm{b}}$, Fu-Zhen Xuan*,a \\ ${ }^{\text {a }}$ Key Laboratory of Pressure System and Safety, MOE, School of Mechanical and Power \\ Engineering, East China University of Science and Technology, Shanghai 200237, P.R China \\ ${ }^{\mathrm{b}}$ Department of Mechanical \& Aerospace Engineering, University of Strathclyde, Glasgow, G1 \\ 1XJ, UK \\ *Corresponding author \\ E-mail: fzxuan@ecust.edu.cn
}

\begin{abstract}
The cyclic plasticity and the low cycle fatigue failure behavior of the weld metal (WM) and base metal (BM) of the CrNiMoV steel welded joint under the strain and stress-control modes were investigated respectively. Significant cyclic softening was observed for both the WM and BM under the low cycle fatigue tests with the two control modes. Besides, obvious ratcheting happened in the $\mathrm{WM}$ and $\mathrm{BM}$ under the stress-controlled cyclic loading conditions. It is shown that both the WM and BM exhibited lower fatigue strength at the stress control mode than that at the strain control mode due to the influence of tension-compression asymmetry. Meanwhile, the WM showed larger cyclic softening rate, lower ratchetting deformation and fatigue strength than the BM under the same loading levels. The failure location of the WM specimens shifted from BM region (nearby the heat affected zone) to the center of WM with the increasing of strain amplitude under the strain-controlled tests, which can be explained with the similar maximum equivalent plastic strain amplitude location shifting behavior observed from the corresponding finite element simulations.
\end{abstract}

Keywords: Cyclic softening; Ratchetting; Low cycle fatigue; Failure location 


\section{Introduction}

For the advantages of high capacity and design manufacture flexibility, welded structures have been widely used in the areas of energy production, aerospace, navigation, bridge engineering, and so on. As the critical parts of a welded structure, welded joints always contains a heat affected zone (HAZ) sandwiched between the weld metal (WM) and base metal (BM) due to the thermal welding, which induces its heterogeneity in both the microstructure and mechanical properties [1,2]. Hence, welded joints are generally considered as the weak regions in the engineering structures. During the service time, the welded structures will unavoidably experience cyclic loadings from the equipment start-up and shut-down process as well as different kinds of dynamic loadings [3,4]. Increased understanding of the cyclic plastic deformation and low cycle fatigue behavior of welded joints is of great importance for the life prediction and safety design of the welded structures.

The strain-controlled low cycle fatigue (LCF) and the stress-controlled ratcheting are the major cyclic deformation phenomena under cyclic loadings [5]. In the last several decades, extensively research works on the strain-controlled LCF behavior of welded joints have been published [6-20]. Taking the joints as bulk material, the cyclic hardening/softening features and the fatigue strength of several homogenous welded joints (with base metal of Ti6Al4V [6], 9-12\% Cr steel [7-8], 7075Al alloy [9], Ni based alloy 617 [4], etc.) and dissimilar welded joints (such as the dissimilar titanium alloy [10-12], the $9 \mathrm{Cr} / \mathrm{CrMoV}$ steel [13], and the 2024/7075 aluminium alloy joints[14]) have been studied by many researchers. It is shown in most works that the welded joints exhibit lower fatigue strength than that of the base metal due to the heterogeneity and welding defects $[15,16]$. Further, in the consideration of the heterogeneity of welded joints, the strain-controlled LCF tests of the individual zones, such as the of BM, WM and HAZ materials have been carried out for different welded joints [2,17-20]. For example, Cheng et al. [2] and Chen et al. [18] investigated the cyclic deformation phenomenon and fatigue lives of the BM, WM and HAZ for the $16 \mathrm{MnR}$ and coke drum welded joints, respectively. The study shows that BM 
exhibited longer fatigue lives than that of the WM or HAZ at all the strain cyclic levels. Due to the mechanical heterogeneity in the welded joints, the cyclic hardening/softening evolutionary characters difference between the BM, WM and HAZ will have important influence on their local stress/strain distribution and redistribution process during the lifetime, which should be mainly considered in the corresponding crack initiation analysis and fatigue life evaluation [21-22]. However, although the basic cyclic hardening/softening phenomenon and fatigue strength at different welded subzones in some welded joints have been studied in the existing research works, the comparative study on the cyclic hardening/softening evolutionary characters, such as the instantaneous cyclic hardening/softening speed during the fatigue life, the cyclic hardening/softening degree at certain life stages and the strain amplitude dependence of the hardening/softening process, between the BM, WM and HAZ are quite limited. Furthermore, it is difficult to determine whether the actual components are under strain or stress-controlled cyclic loadings during the service process since strains and stress are related to each other [22-23]. And it is reported that the strain fatigue curves under the strain and stress-controlled conditions are significantly different for some materials [24-25]. It is desirable to study the ratcheting behavior of welded joints and to explore the difference of the cyclic deformation and fatigue features for welded joints under the stress and strain control modes [22]. For the stress-controlled ratcheting behavior of welded joints, Wang et al. $[5,26]$ conducted a series of tests for the 304L base metal and ER308L weld metal of the $304 \mathrm{~L}$ stainless steel welded joint under the stress cycles with various magnitudes of mean stress, in which the BM and WM showed cyclic hardening and cyclic softening ratchetting strain evolution process, respectively. Nevertheless, limited research works were reported in the past on the ratchetting test and its contribution to the fatigue life for the welded joints, the comparative study on the cyclic deformation and fatigue behavior of welded joints under the stress and strain control modes has not been examined in literature. In addition, due to the significant heterogeneity in microstructure and local properties, the LCF failure location of welded joints may be influenced or shift with the changing of the loading levels or environment temperature 
$[8,13]$. Under the cyclic stress-controlled loadings, the local deformation distributions in the welded joints were studied by Luo et al. [21] and Corigliano et al. [27] by the digital image correlation method. However, few studies on the observation and mechanism explanation of failure location shifting in the welded joints under cyclic loadings were available in the open literature.

Finally, stand at the angle of the material, the NiCrMoV steels are widely used in the welded rotors in the nuclear power plant due to high fatigue strength and good stress corrosion resistance property. However, the existing studies concerning the $\mathrm{NiCrMoV}$ steel welded joint are mainly focused on the microstructure and local mechanical behavior [28-29], the very high cycle fatigue behavior [30], the stress corrosion cracking [31-32] and fatigue crack growth [33]. There are no research works for LCF and ratchetting behaviors of the NiCrMoV steel welded joint in the published literatures.

In this work, the cyclic plasticity behavior and LCF failure features of the BM and WM of NiCrMoV steel welded joint were investigated under the strain and stresscontrolled cyclic loadings. Simultaneously, comparative studies on the local mechanical properties distribution cross the welded region, the mean stress relaxation, cyclic softening evolutionary characters and ratchetting evolution behavior of BM and WM for NiCrMoV steel welded joint were carried out with different loading levels and stress ratios. Moreover, the strain fatigue curves of the BM and WM, as well as the fatigue failure behavior of welded joints under different strain/stress amplitudes were analyzed and discussed with these two control modes being considered. And The fatigue failure locations shifting behavior in the WM specimens was explained by the maximum equivalent plastic strain amplitude distribution obtaining from cyclic finite element simulations.

\section{Experimental and numerical procedures}

\subsection{Material and welded joint}

The NiCrMoV steel welded joint was investigated in this work, which was welded 
by the submerged arc welding technique and schematically shown in Fig. 1. After the submerged arc welding process, a post weld heat treatment under furnace cooling was carried out at $580{ }^{\circ} \mathrm{C}$ for $20 \mathrm{~h}$ to reduce welding residual stress, with the charge temperature under $400{ }^{\circ} \mathrm{C}$ and heating rate under $55^{\circ} \mathrm{C} / \mathrm{h}$. This is the as-received condition of the welds (Fig. 1). The NiCrMoV steel BM undergoing quenching and tempering treatments before welding has a chemical composition (in wt.\%) of: $\mathrm{Si} \leq$ 0.12, C 0.18-0.27, P $\leq 0.015, \mathrm{Mn} 0.12-0.28$, Ni 2.05-2.35, $\mathrm{S} \leq 0.015, \mathrm{Su} \leq 0.17, \mathrm{Cr}$ 2.15-2.45, Mo 0.63-0.82, $\mathrm{V} \leq 0.12$, and $\mathrm{Fe}$ as the balance. Whereas, the WM has a chemical composition (in wt.\%) of: Si 0.2, C 0.12, Mn 1.48, P 0.005, S 0.005, Ni 2.18, $\mathrm{Cr}$ 0.57, Mo 0.51, and $\mathrm{Fe}$ as the balance. In addition, sample locations of specimens used in the cyclic loading tests in this paper are also shown in Fig. 1, which will be introduced in detail in the following paragraphs.

\subsection{Localized mechanical test of the welded joints}

As shown in Fig. 1, the welded joint contains the BM, WM and HAZ, which lead to significant mechanical heterogeneity to the joint. Then an optical micrograph around HAZ is shown in Fig. 2. Fig.2 shows that the microstructures of the BM, WM and HAZ are quite different, and the width of the HAZ is about $2 \mathrm{~mm}$. In order to get a much clearer comparation, the microstructures in different regions of the welded joint were observed by optical microscope, as shown in Fig. 3. It can be seen from Fig. 3 that the microstructures of BM are mainly large blocky tempered lathy martensites and a small amount of granular tempered bainites (Fig. 3(a)), and the microstructures of WM are mainly the needlelike bainites with some $\delta$-ferrites distribute parallelly on the matrix (Fig. 3(b)). It is also shows that the Granular tempered martensites with small grain size distribute uniformly in HAZ (Fig .3c). To obtain the local mechanical distributed situation along the welded joint, the nanoindentation tests and micro-tensile tests at different locations in BM, WM and HAZ were carried out at room temperature. As shown in Fig. 2, a cuboid sample with dimension of $40 \mathrm{~mm} \times 20 \mathrm{~mm} \times 8 \mathrm{~mm}$ was first cut from the as-received welded joints with the WM section in central. Then part of the cuboid sample was cut off along line AB (Fig. 2) 
and reprocessed for nanoindentation tests, while the other part was machined to micro-tensile specimens at the sections of BM, WM, and HAZ, as shown in Fig. 2. In the nanoindentation tests, the hardness and elastic module at different locations were measured using Berkovich type diamond tip base on Nano Indenter G200 and Oliver and Pharr method $[34,35]$. In order to reduce test randomness, a $n$ ' $\times 3$ location array was designed along line $\mathrm{AB}$ in the welded joint sample (Fig. 2), where $n$ ' means the number of indentation locations along the welded joint, the number 3 means three repeat tests for locations with the same distance to the weld center. Finally, the indentation tests with a peak indentation depth of $600 \mathrm{~nm}$ and holding time of $15 \mathrm{~s}$ were proceeded at all the locations in the $n ’ \times 3$ array. Furthermore, the micro-tensile tests for micro samples cutting from BM, HAZ, and WM (Fig. 2) were conducted on

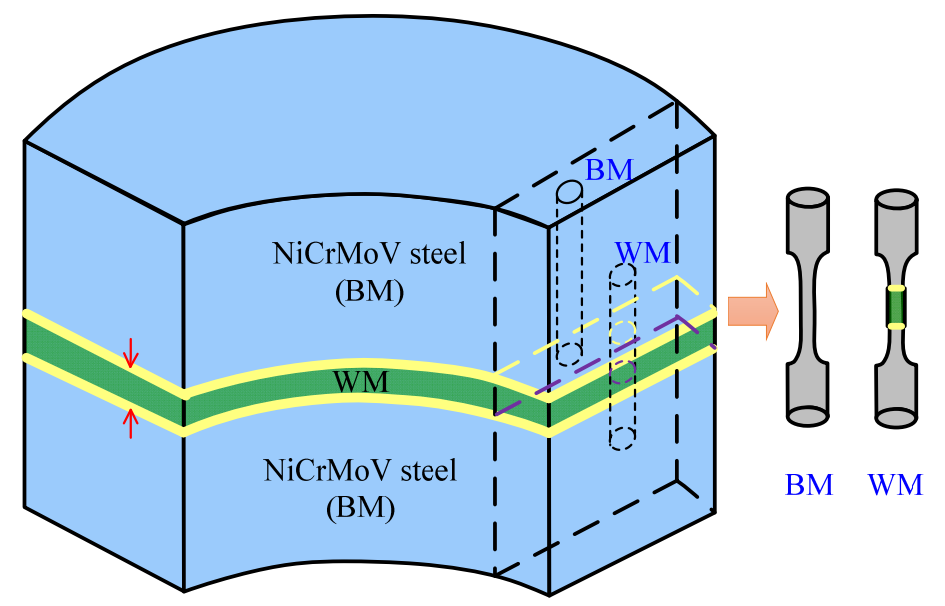

Fig. 1 Schematic diagram of the welded joint and locations of the specimens

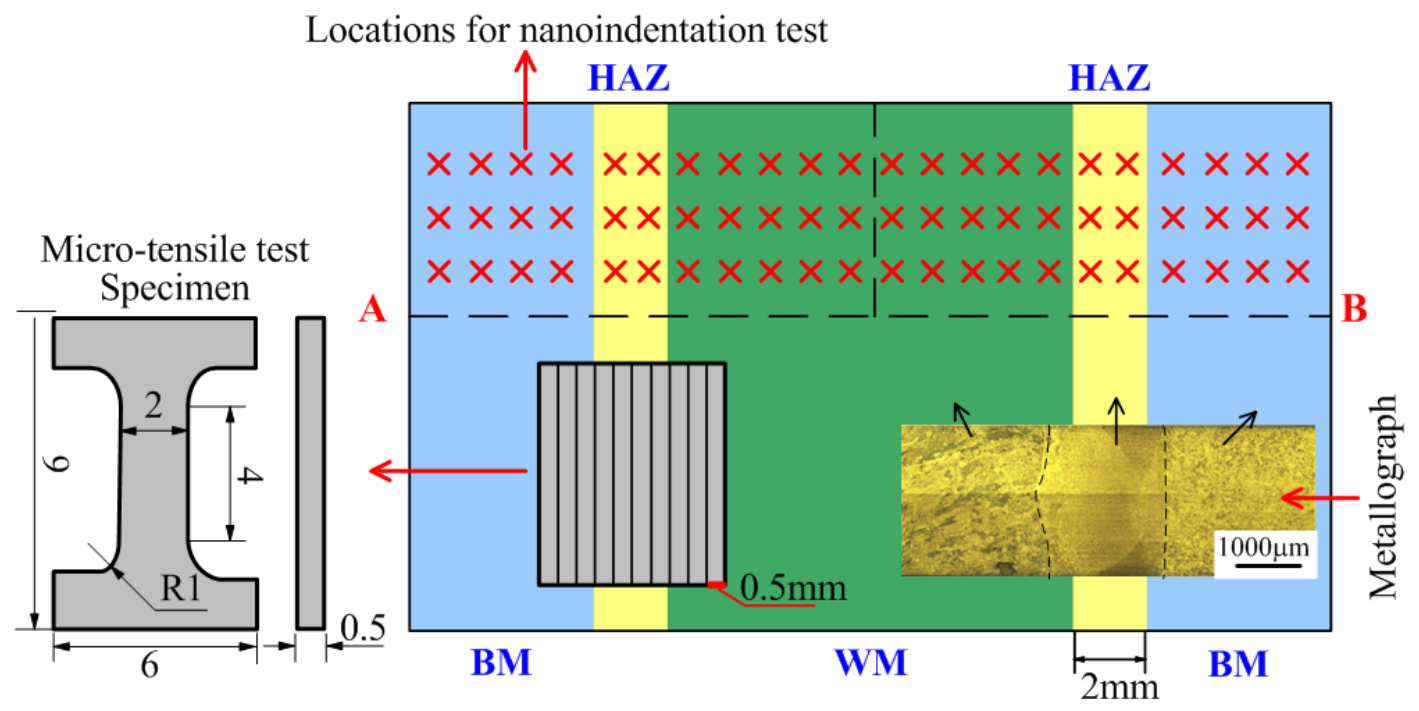

Fig. 2 Sketch for the locations of the Nano-identation tests and the micro-tensile specimen 

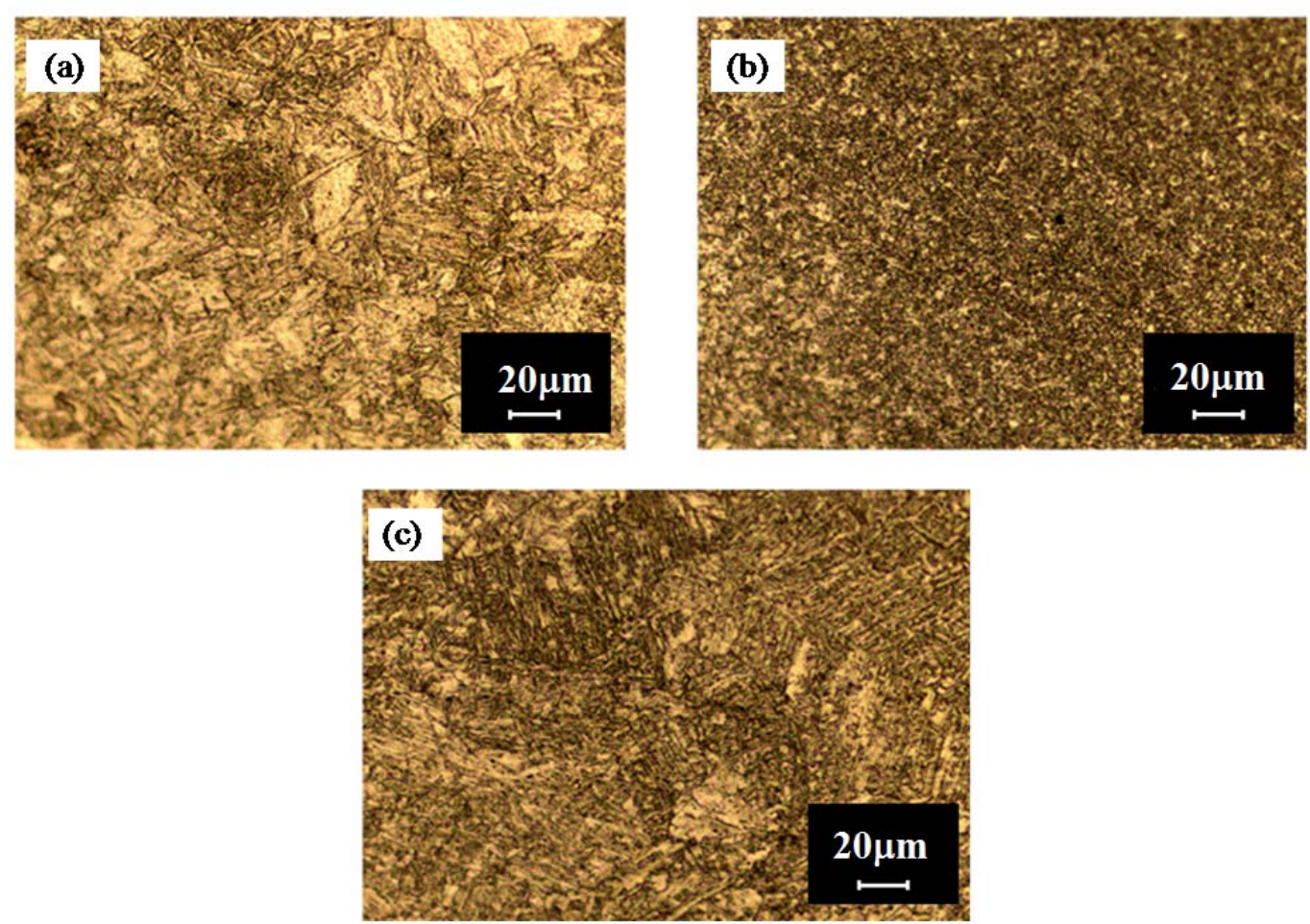

Fig. 3 The microstructures in the different regions of the welded joint:

(a) base metal (BM); (b) heat affected zone (HAZ); (c) weld metal (WM)

the in-situ tensile device (Deben UKL td), during which the displacement controlled mode was employed with a displacements rate of $0.1 \mathrm{~mm} / \mathrm{min}$ and the load response were automatically recorded.

\subsection{The cyclic loading tests}

In the present work, the monotonic tensile tests, the strain-controlled LCF tests and the stress-controlled ratchetting tests for the NiCrMoV WM and $\mathrm{BM}$ were carried out at room temperature. The solid cylinder specimens used in the cyclic tests for the WM and BM were extracted from the locations shown in Fig. 1. The specimens were machined with uniform gauge section of $11 \mathrm{~mm}$ in diameter and $32 \mathrm{~mm}$ in length, as displayed in Fig. 4(a) and (b). To guarantee a smooth surface for the fatigue tests, all the specimens were polished to a surface roughness down to $0.2 \mu \mathrm{m}$. All the fatigue tests were performed on Instron 8032 servo-hydraulic machine, during which the strain was monitored with an extensometer within an axial $12.5 \mathrm{~mm}$ gauge length attaching to the specimen in the gauge section, and the stress was obtained from the load response monitored by a load cell. The monotonic and fatigue samples were 
manufactured and tested under the standards of ASTM E8M-2004, ASTM E606-2004 (strain-controlled) and ASTM E466-2007 (stress-controlled), respectively. The detailed loading conditions for the strain/stress conditions of the WM and BM are listed in Table 1, where $\mathrm{R}$ denotes the strain or stress ratio in the tests. Monotonic tension tests for the WM and BM were carried out at the strain rate of $0.0001 \mathrm{~s}^{-1}$. In the strain-controlled LCF tests, the triangular loading waveforms with strain ratio $\mathrm{R}=-1$ were employed with a strain rate of $0.008 \mathrm{~s}^{-1}$ and strain amplitudes ranging from $0.3 \%$ to $0.8 \%$. A $40 \%$ drop in cyclic maximum tensile stress after 50 cycles was defined as the failure criterion [36]. For the stress-controlled ratchetting tests, the triangular loading waveforms were also used with a stress rate of $500 \mathrm{MPa} \mathrm{s}^{-1}$ for both the WM and BM, and the failure life was obtained as the cycle number corresponding to fracture [22]. The loading conditions of the ratcheting tests were first carried out with stress amplitudes of $618 \mathrm{MPa}, 625 \mathrm{MPa}, 650 \mathrm{MPa}, 700 \mathrm{MPa}$, and $735 \mathrm{MPa}$, stress ratio $\mathrm{R}=-1$ for the $\mathrm{WM}$ (WR1 5 in Table 1). Then the ratcheting tests with stress amplitudes of $618 \mathrm{MPa}, 625 \mathrm{MPa}$ and $650 \mathrm{MPa}$, stress ratio $\mathrm{R}=-1$ were applied for the $\mathrm{BM}$ (BR1 3 in Table 1) to do the ratcheting comparison between the WM and BM. Finally, the stress-controlled ratchetting tests with peak stress of $625 \mathrm{MPa}$, stress ratio varied from -1.05 to -0.8 were conducted on the WM to reveal the influence of stress ratio on the ratchetting of the WM. It should be mentioned that the ratchetting strain in this work is defined as [37]

$$
\varepsilon_{r}=\frac{1}{2}\left(\varepsilon_{\max }+\varepsilon_{\min }\right)
$$

where $\varepsilon_{\max }$ and $\varepsilon_{\min }$ are the maximum and minimum axial strain in each cycle during the lifetime. Parallel tests for the same loading conditions were conducted to reduce the effect of data scattering. It is also worth noting that although the WM specimen consist of WM, HAZ and BM, the gauge length of the extensometer is calibrated to be $12.5 \mathrm{~mm}$, which is covered by the WM section shown in Fig. 4(b) and just reflecting the strain for the WM in the specimen. Meanwhile, during the fatigue tests, the stress for the sections of WM, HAZ and BM were with the same value due to the equilibrium of forces. As a consequence, the corresponding cyclic stress-strain 
response obtained from each WM specimen was taken as that of the welded metal in this paper. The similar situation and handling method also existed in the research works carried out by Cheng et al. [2], Wang et al. [5], and Zhang et al. [20].

(a)

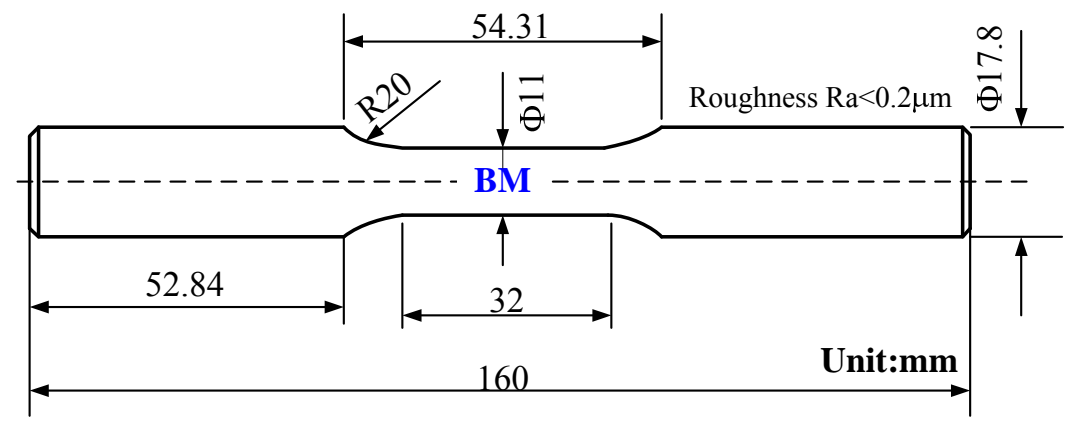

(b)

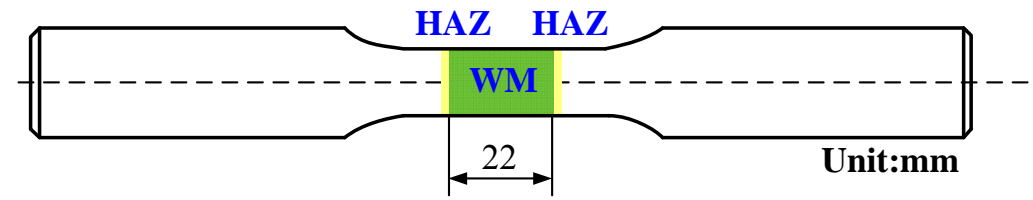

Fig. 4 The geometry of specimens for cyclic loading tests:

(a) base metal(BM); (b) weld metal (WM)

\subsection{Numerical procedures}

The finite element code ABAQUS was employed to simulate the local deformation distributions of the WM specimens at the half-life cycle for different applied strain amplitudes $(0.8 \%, 0.5 \%, 0.4 \%, 0.33 \%$ and $0.3 \%)$. The axisymmetric specimen model was constructed by employing the axisymmetric 8-node elements (CAX8), as shown in Fig. 5. In order to get better convergence in the finite element simulations the elements size near the material junction zone in Fig. 5 was set to be about $0.3 \mathrm{~mm}$. In the simulations, the cyclic strain was simulated by applying displacement at the ending of each specimen. The applied cyclic displacement amplitude was determined by controlling the average strain amplitude in the extensometer covered section as $0.8 \%, 0.5 \%, 0.4 \%, 0.33 \%$ and $0.3 \%$, respectively. To simulate the stress and strain field in the WM specimen at the half-life cycle, the BM and WM was treated as the elastic-plastic materials and described with the cyclic stress-strain relations. The constitutive model employed for the BM and WM is the Ramberg-Osgood model [13], which can be expressed as:

$$
\frac{\Delta \sigma}{2}=K \underset{9}{\left(\frac{\Delta \varepsilon_{p}}{2}\right)^{n}}
$$


where $\Delta \sigma / 2$ and $\Delta \varepsilon_{p} / 2$ is the stress amplitude and plastic strain amplitude at the half life cycle, respectively, $K$ is the cyclic strength coefficient and $n$ is the cyclic hardening exponent, the value of which will be exhibit in Section 3.2.3. Meanwhile, the HAZ was considered as elastic material due to the extremely higher hardness and yield stress observed in the nanoindentation and micro-tensile tests, which will be shown in Section 3.1. The dimension of HAZ was set to be $2 \mathrm{~mm}$ according to the optical micrograph in Fig. 2.

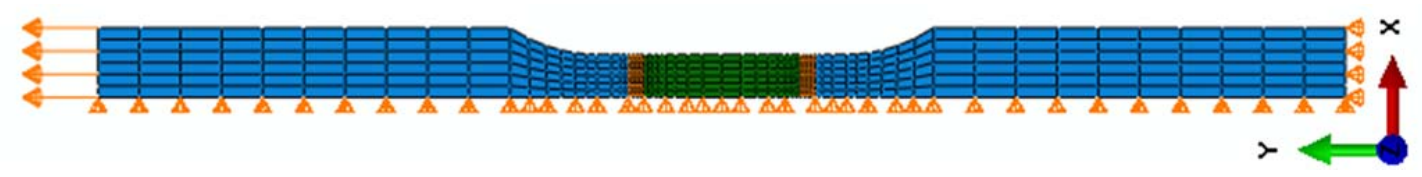

Fig. 5 The finite element meshes of the WM specimen.

Table 1 Detail of all the loading conditions.

\begin{tabular}{|c|c|c|c|c|c|}
\hline Specimen & Test type & NO. & $\mathrm{R}$ & Loading condition & Loading rate \\
\hline \multirow[t]{16}{*}{ WM } & Monotonic tension & W1 & 1 & l & $0.0001 \mathrm{~s}^{-1}$ \\
\hline & \multirow[t]{5}{*}{ Strain LCF test } & WS1 & -1 & $\pm 0.8 \%$ & $0.008 \mathrm{~s}^{-1}$ \\
\hline & & WS2 & -1 & $\pm 0.5 \%$ & $0.008 \mathrm{~s}^{-1}$ \\
\hline & & WS3 & -1 & $\pm 0.4 \%$ & $0.008 \mathrm{~s}^{-1}$ \\
\hline & & WS4 & -1 & $\pm 0.33 \%$ & $0.008 \mathrm{~s}^{-1}$ \\
\hline & & WS5 & -1 & $\pm 0.3 \%$ & $0.008 \mathrm{~s}^{-1}$ \\
\hline & \multirow[t]{10}{*}{ Ratcheting test } & WR1 & -1 & $\pm 735 \mathrm{MPa}$ & $500 \mathrm{MPa} \mathrm{s}^{-1}$ \\
\hline & & WR2 & -1 & $\pm 700 \mathrm{MPa}$ & $500 \mathrm{MPa} \mathrm{s}^{-1}$ \\
\hline & & WR3 & -1 & $\pm 650 \mathrm{MPa}$ & $500 \mathrm{MPa} \mathrm{s}^{-1}$ \\
\hline & & WR4 & -1 & $\pm 625 \mathrm{MPa}$ & $500 \mathrm{MPa} \mathrm{s}^{-1}$ \\
\hline & & WR5 & -1 & $\pm 618 \mathrm{MPa}$ & $500 \mathrm{MPa} \mathrm{s}^{-1}$ \\
\hline & & WR6 & -0.8 & $+625 /-500$ & $500 \mathrm{MPa} \mathrm{s}^{-1}$ \\
\hline & & WR7 & -0.88 & $+625 /-550$ & $500 \mathrm{MPa} \mathrm{s}^{-1}$ \\
\hline & & WR8 & -1.02 & $+625 /-635$ & $500 \mathrm{MPa} \mathrm{s}^{-1}$ \\
\hline & & WR9 & -1.03 & $+625 /-645$ & $500 \mathrm{MPa} \mathrm{s}^{-1}$ \\
\hline & & WR10 & -1.05 & $+625 /-655$ & $500 \mathrm{MPa} \mathrm{s}^{-1}$ \\
\hline \multirow[t]{9}{*}{$\mathrm{BM}$} & Monotonic tension & B1 & 1 & / & $0.0001 \mathrm{~s}^{-1}$ \\
\hline & \multirow[t]{5}{*}{ Strain LCF test } & $\mathrm{BS} 1$ & -1 & $\pm 0.8 \%$ & $0.008 \mathrm{~s}^{-1}$ \\
\hline & & $\mathrm{BS} 2$ & -1 & $\pm 0.5 \%$ & $0.008 \mathrm{~s}^{-1}$ \\
\hline & & $\mathrm{BS} 3$ & -1 & $\pm 0.4 \%$ & $0.008 \mathrm{~s}^{-1}$ \\
\hline & & BS4 & -1 & $\pm 0.33 \%$ & $0.008 \mathrm{~s}^{-1}$ \\
\hline & & BS5 & -1 & $\pm 0.3 \%$ & $0.008 \mathrm{~s}^{-1}$ \\
\hline & \multirow[t]{3}{*}{ Ratcheting test } & BR1 & -1 & $\pm 650 \mathrm{MPa}$ & $500 \mathrm{MPa} \mathrm{s}^{-1}$ \\
\hline & & BR2 & -1 & $\pm 625 \mathrm{MPa}$ & $500 \mathrm{MPa} \mathrm{s}^{-1}$ \\
\hline & & BR3 & -1 & $\pm 618 \mathrm{MPa}$ & $500 \mathrm{MPa} \mathrm{s}^{-1}$ \\
\hline
\end{tabular}




\section{Results and discussion}

\subsection{The mechanical heterogeneity of the welded joint}

Fig. 6(a) and (b) show the average local hardness and yield stress distribution obtaining from the nanoindentation tests and the micro-tension tests across the welded joint, respectively, while the yield stress was determined from the criterion of stress values at a strain value of $0.2 \%$. It is shown that the distribution of the hardness and yield stress in the welded joint are almost symmetric in the vicinity of the weld center. The maximum hardness and maximum yield stress are focused in the HAZ, which is much higher than that in the sections of BM and WM. The hardness and yield stress in the WM are slightly larger than those in the BM. Another important point is that the yield stress in HAZ is about 250MPa higher than that in the WM, which indicate that the HAZ in the WM specimen (Fig. 4) hardly yields during the cyclic tests due to the equivalent average stress in the three welded sections. It is also worth noting that the average elastic module obtained from the nanoindentation tests of the BM, WM and HAZ is about $182.5 \mathrm{GPa}, 197.0 \mathrm{GPa}$, and 228.8GPa, respectively. The HAZ exhibits much higher tensile strength than BM and WM, which is caused by its special microstructures (small and uniformly distributed granular tempered martensite) introduced by welding and post weld heat treatment process as shown in Fig.3 (b).

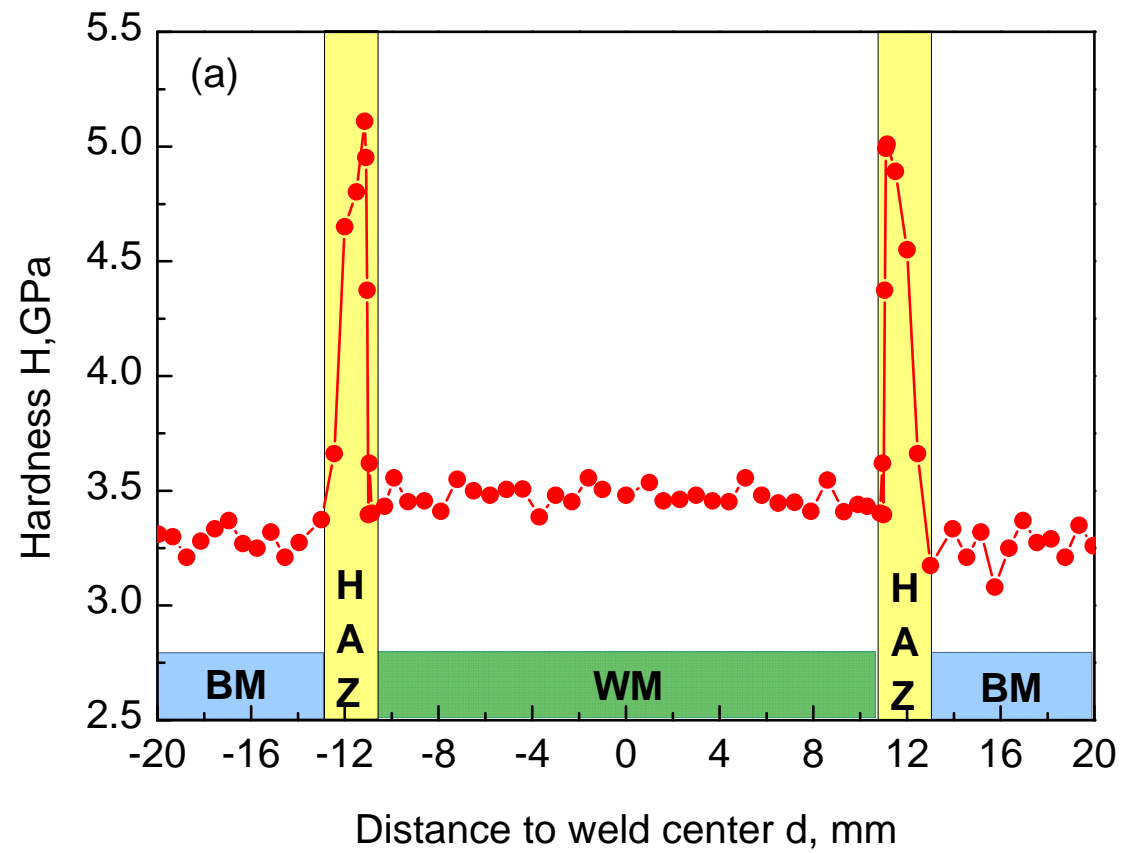




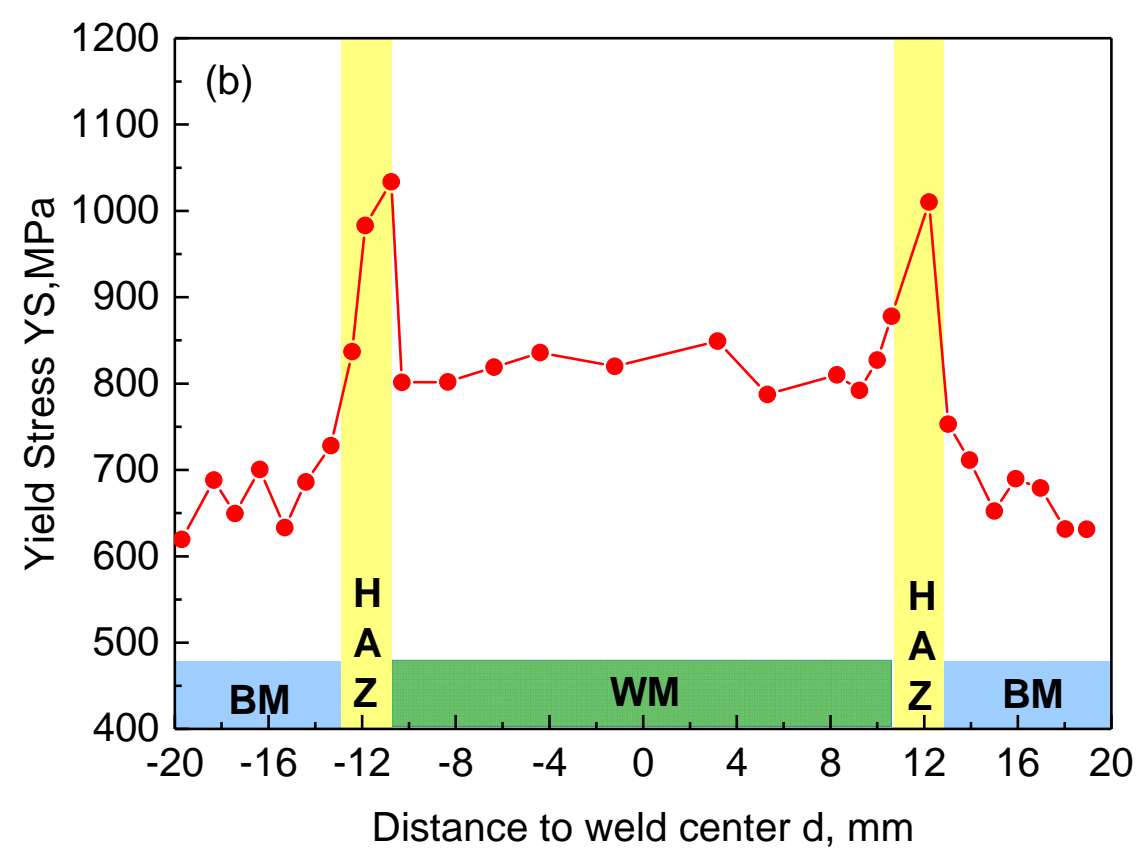

Fig. 6 The local mechanical distribution of the welded joint: (a) the hardness; (b) the yield stress 3.2 The cyclic plasticity behavior of welded joint under strain-controlled condition

\subsubsection{Cyclic softening of the WM and BM}

Under the cyclic loading conditions of WS1 WS5 and BS1 BS5 listed in Table 1, the strain-controlled LCF tests with strain ratio $\mathrm{R}=-1$ were carried out for the $\mathrm{WM}$ and BM. Fig. 7 shows the evolution curves of the stress amplitude responses for the WM and BM at different strain amplitudes during the whole LCF life, respectively. The horizontal axis represents the number of cycles normalized by the final failure cycles. It is shown that both the WM and BM exhibit continuous cyclic softening behavior without a cyclic stabilized stage until the failure life, and the stress amplitude of WM is higher than that of the BM at the same applied strain amplitude level. With the decreasing of the strain amplitude, the stress amplitude response decreases in both the WM and BM. Furthermore, the stress amplitude response curves of the WM and BM are with similar evolution tendency, which can be divided into three stages: (1) the first stage is from the beginning of the LCF process to about $20 \% \sim 30 \%$ fatigue life, during which both the WM and BM exhibit obvious cyclic softening; (2) the second stage covers the $20 \% \sim 30 \%$ to about $90 \%$ of the fatigue life, and the $\mathrm{WM}$ and $\mathrm{BM}$ keep linear cyclic softening behavior in this stage; (3) the third stage is corresponding to the last $10 \%$ fatigue life, during which both the WM and BM suffer a rapid 
softening process until the final specimens failure. It can also be seen that the stress amplitude difference between the WM and BM become more and more smaller from the first stage to the third stage, which indicate that the two materials may have different softening speed during the low cycle fatigue process.

The stress amplitude response evolution of cyclic softening material over lifetime can be determined by the softening factor $S F$ and the instantaneous softening rate of at a certain cycle $N$, as shown in Fig. 8. In this paper, a transient softening factor removing effect of strain levels $[22,38]$ is introduced to analyze the cyclic softening degree evolution of the WM and BM during the fatigue life, which can be defined as:

$$
S F=\frac{\left.\sigma_{a}\right|_{N}-\left.\sigma_{a}\right|_{N_{f} / 2}}{\left.\sigma_{a}\right|_{N}} \times 100 \%
$$

where $\left.\sigma_{a}\right|_{N}$ is the stress amplitude at a certain cycle, $\left.\sigma_{a}\right|_{N_{f} / 2}$ is stress amplitude at the half life cycle. Using Eq. (3), the evolution curves of transient softening factors (SF) for WM and BM under the strain-controlled cyclic loadings of WS1 WS5 and BS1 BS5 (Table 1) are calculated and depicted in Fig. 9(a) and (b), respectively. It can be observed in Fig. 9 that for both the WM and BM, the SF converges on a single curve with three stages at the higher strain amplitudes (such as $0.4 \%, 0.5 \%$ and $0.8 \%$ ). While for the lower strain amplitudes of $0.33 \%$ and $0.3 \%$, the SF decreases with the reduction of the strain amplitude at the cycles before the $50 \%$ fatigue life, and converges together with the other loading levels again after the $50 \%$ fatigue life. Since most amount of the cyclic softening occurred before the half life, the above phenomenon indicates that the cyclic softening behaviors of the WM and BM are both strain amplitude dependent at lower strain amplitude levels. Similar phenomenon has been observed previously by Nagesha et al. [39], Fournier et al. [40], Guguloth et al. [41] and $\mathrm{Wu}$ et al. [42], which was ascribed to different mechanisms of micro-structural changes at various strain amplitudes [42]. In order to compare the SF differences between the WM and BM, the SF curve of WM under the strain amplitude of $0.8 \%$ is also plotted in Fig. 9(b), it can be concluded that the WM always exhibit higher SF than BM at the same loading levels, and WM shows more obvious strain 
amplitude dependent feature than BM, especially at the stage in the first $50 \%$ fatigue life. Furthermore, Fig. 10 shows the evolution of instantaneous softening speed $\mathbb{\&}$ ( of $=-\frac{\partial \sigma_{a}}{\partial N}$ ) for the WM and BM at different fatigue life stages and various strain amplitudes with histogram. As presented in Fig. 10, while the strain amplitude varying from $0.3 \%$ to $0.8 \%$ and the fatigue stage changing from $10 \%$ to $80 \%$ fatigue life, the values of $\mathbb{E}_{a}$ of the WM are always higher than those of the BM, which can explain why the evolution curve of the stress amplitude response for the WM and BM get closer to each other during the fatigue life shown in Fig. 7. For both the WM and $\mathrm{BM}$, the increasing the strain amplitude from $0.3 \%$ to $0.8 \%$ leads to increase of the instantaneous softening speed $\mathbb{Q}$, and the higher the strain amplitude is, the faster the $\frac{\&}{d}$ increases. It is also worth noting that at various applied strain amplitude conditions $(0.3 \% \sim 0.8 \%)$ for both $\mathrm{WM}$ and $\mathrm{BM}$, the instantaneous softening rate of is large and decrease sharply in the first 10\% 30\% life stage, then it becomes lower and drops smoothly until the $80 \%$ life stage just before failure, which brings into correspondence with the continue cyclic softening process of WM and BM.

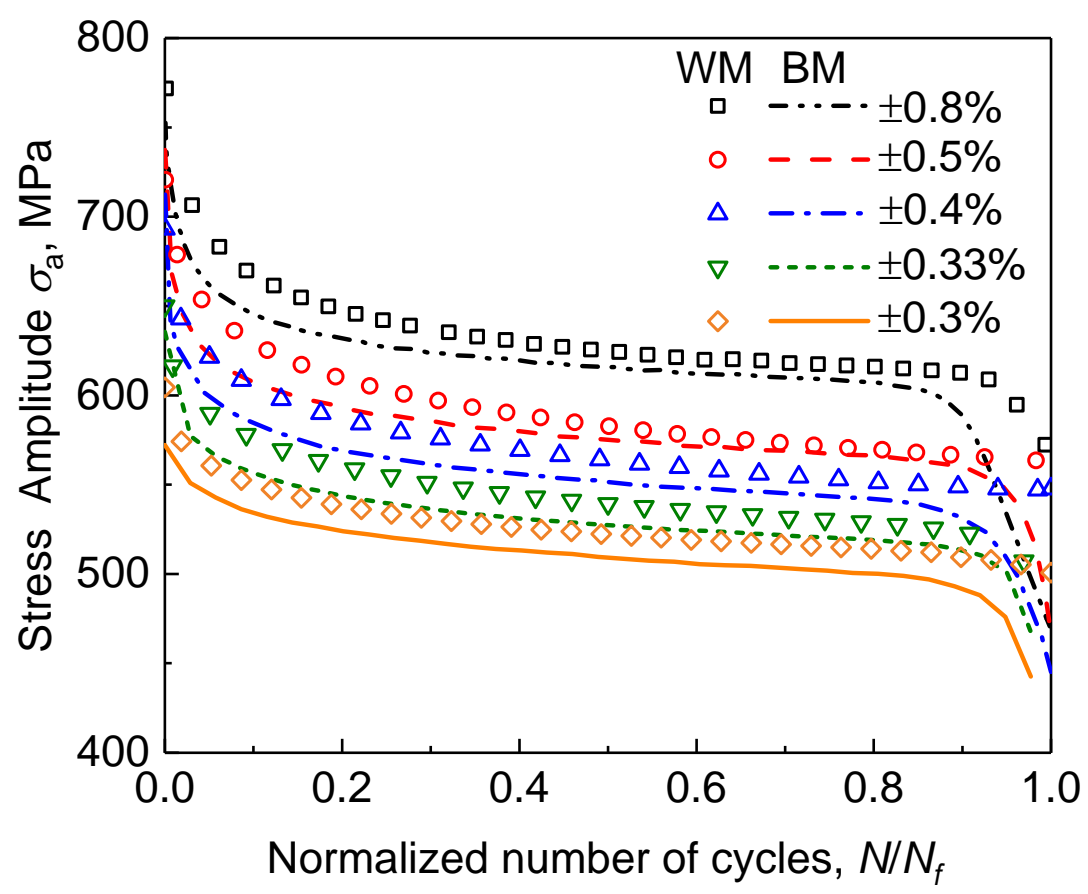

Fig. 7 Evolution curve of stress amplitudes in the strain-controlled fatigue tests for WM and BM 


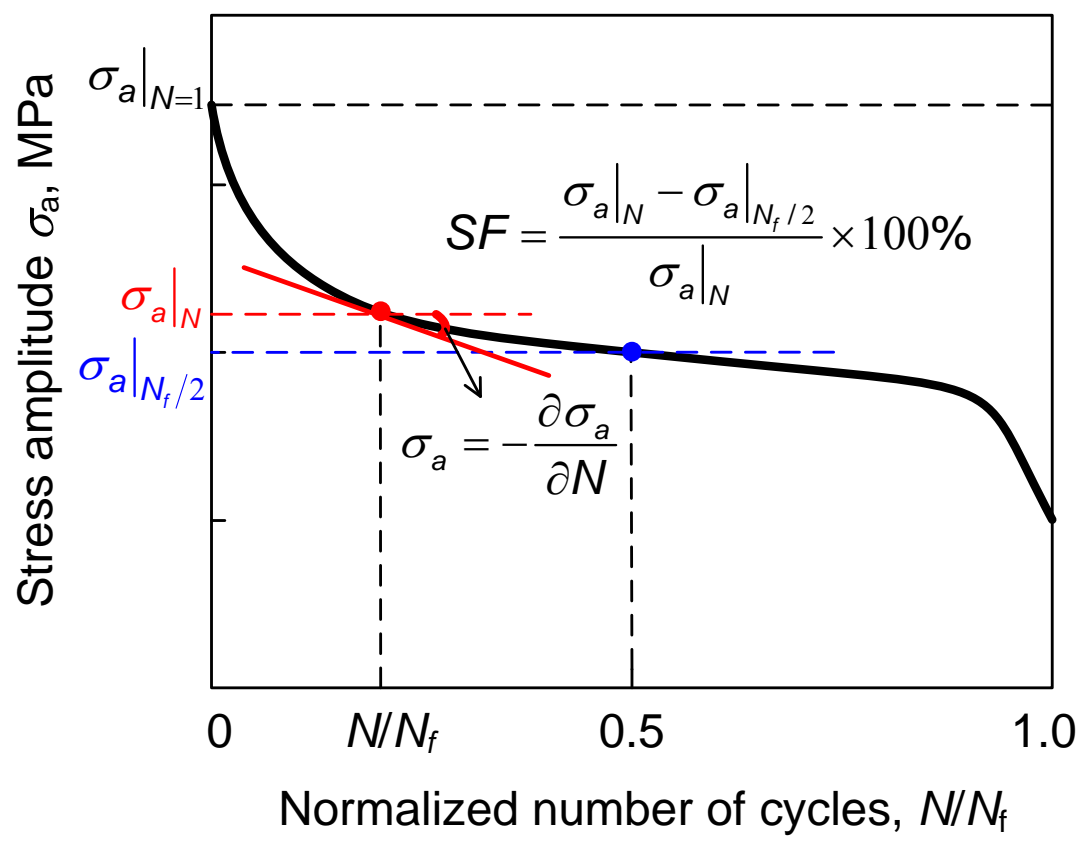

Fig. 8 The schematic diagram of transient softening factors $(S F)$ and instantaneous softening speed $\&$

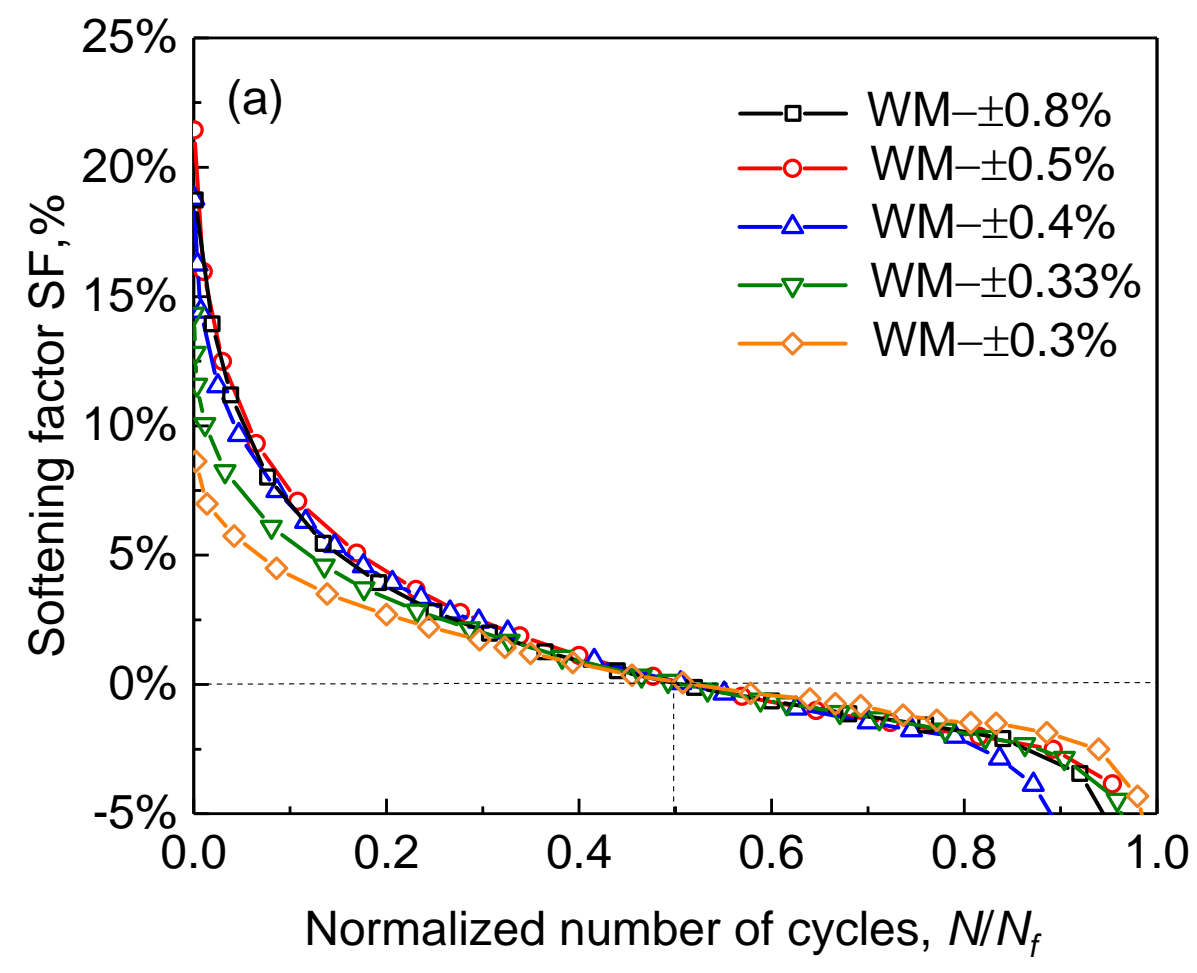




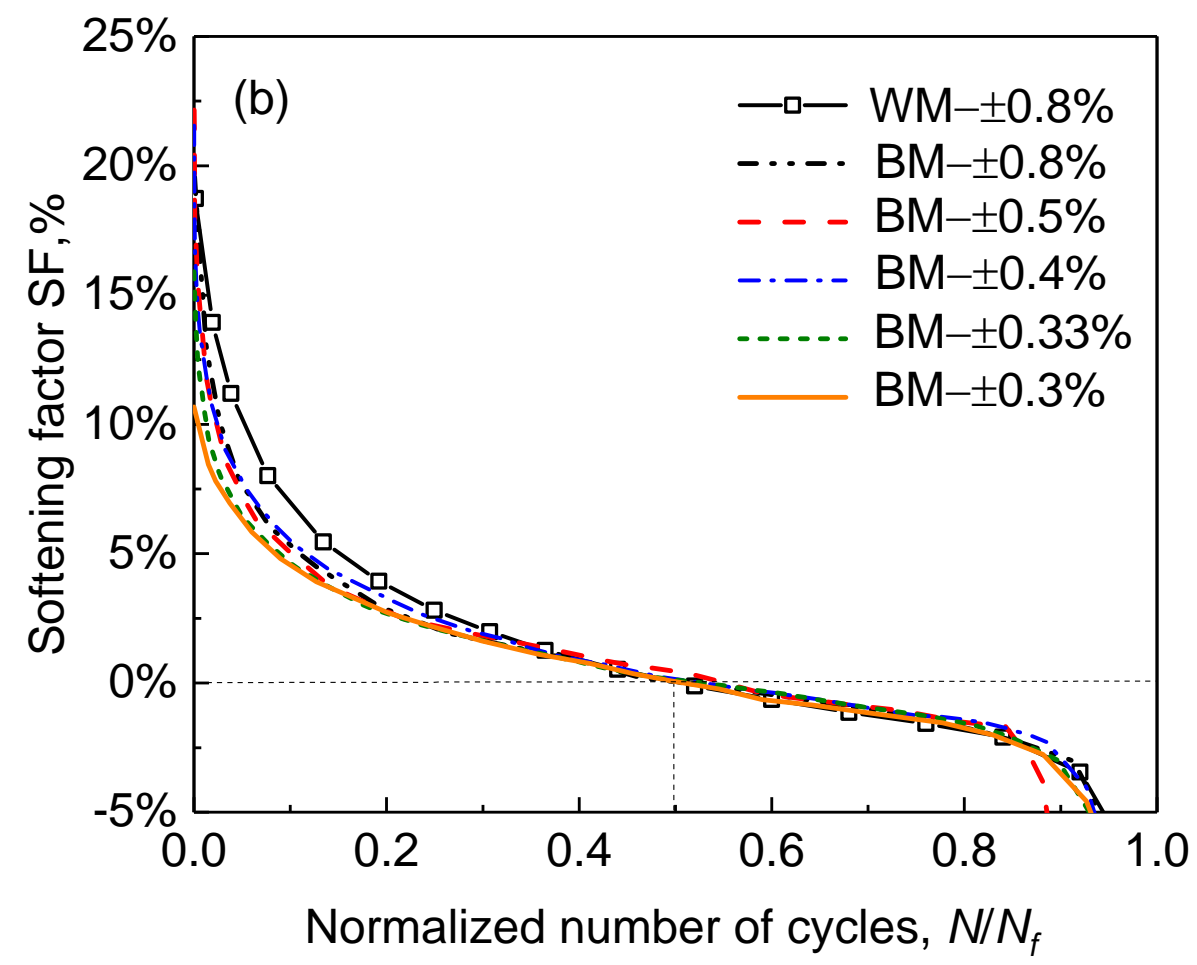

Fig. 9 Evolution curve of $S F$ with fatigue life for the strain-controlled fatigue tests:

(a) weld metal (WM); (b) base metal(BM)

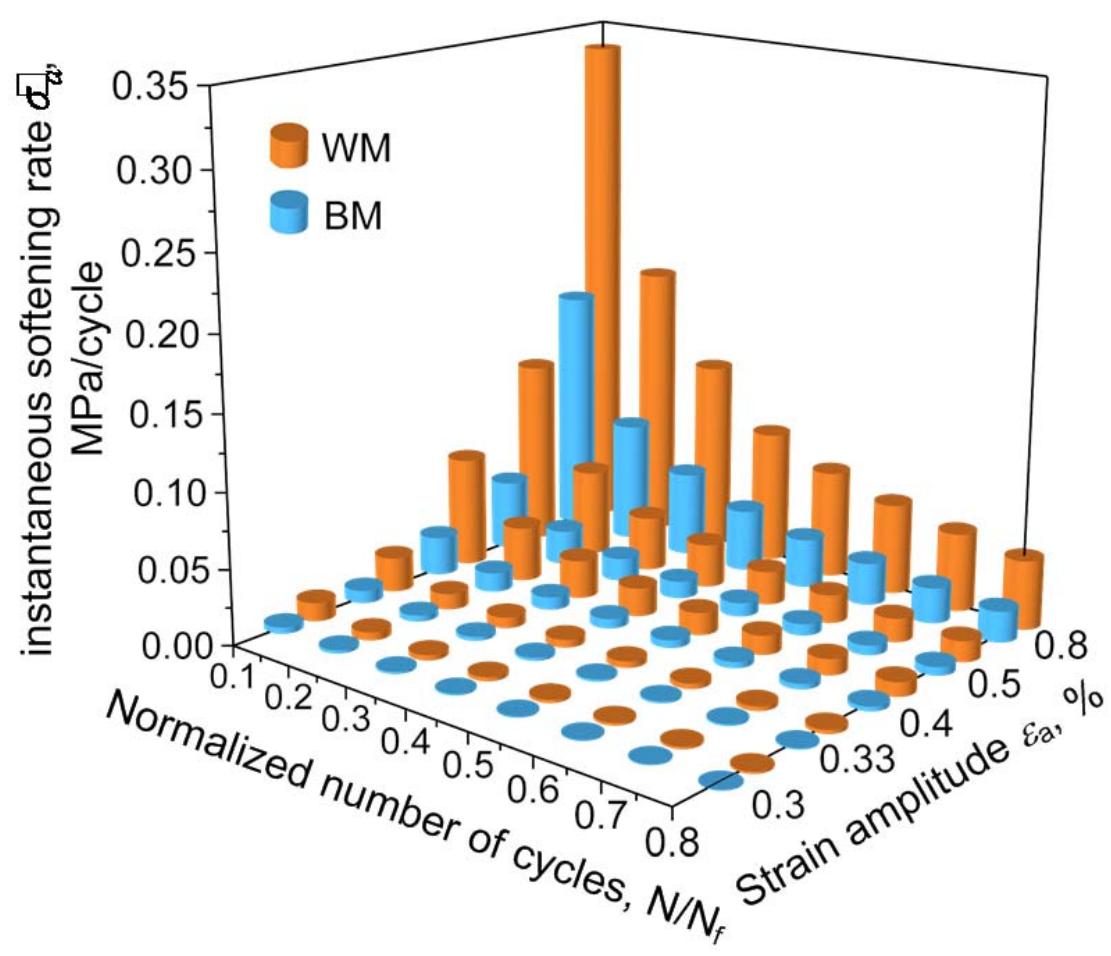

Fig. 10 The instantaneous softening speed $\mathbb{Q}_{\text {for }}$ the WM and BM at different fatigue life stage and varying strain amplitudes 


\subsubsection{Mean stress relaxation of the WM and BM}

It is shown that the mean stress has significant effects on the fatigue life of the engineering materials and mechanical components [42-45]. Several fatigue life prediction models have taken into account the effect of mean stress, such as Morrow model [46], SWT model [47], and the modified Goodman diagram [43]. The mean stress has also been found to be cycle-dependent variation, such as relaxation, which may significantly affect the fatigue life [45]. In this section, the mean stress relaxation behavior of the WM and BM under strain cyclic loadings of WS1 WS5 and BS1 BS5 (Table.1, $\pm 0.3 \% \sim 0.8 \%$ ) is analyzed and discussed. As displayed in Fig. 11, the mean stress relaxation range $\mathrm{V} \sigma_{\mathrm{m}}$ and the final stable mean stress $\sigma_{\mathrm{ms}}$ of WM and BM along with the strain amplitude are represented by different symbols, in which the $\Delta \sigma_{\mathrm{m}}$ is defined as:

$$
\Delta \sigma_{\mathrm{m}}=\sigma_{\mathrm{ms}}-\left.\sigma_{\mathrm{m}}\right|_{N=1}
$$

where $\left.\sigma_{\mathrm{m}}\right|_{N=1}$ is the mean stress at the first cycle, and $\Delta \sigma_{\mathrm{m}}$ is used to reflect the mean stress relaxation degree in the $\mathrm{WM}$ and $\mathrm{BM}$. It is clear that $\Delta \sigma_{\mathrm{m}}$ of $\mathrm{BM}$ is approximately equal to zero for all the strain amplitude varying from $0.3 \% \sim 0.8 \%$, which means that there's almost no mean stress relaxation in the BM during the fatigue life. Meanwhile, the stable values of mean stress $\sigma_{\mathrm{ms}}$ in BM vary in the range of $0 \sim-7.5 \mathrm{MPa}$ and decrease linearly with the increasing of strain amplitude $(0.3 \% \sim 0.8 \%)$. The values of mean stress of BM during the fatigue life are negative but with relatively small magnitudes. However, the values of $\Delta \sigma_{\mathrm{m}}$ of WM (in the range of $25 \sim 5 \mathrm{MPa}$ ) are larger than those of $\mathrm{BM}$, and decrease linearly with the increasing of strain amplitude $(0.3 \% \sim 0.8 \%)$. The stable mean stress $\sigma_{\mathrm{ms}}$ in WM keeps a constant value of $-10 \mathrm{MPa}$ for all the applied strain amplitudes. It can be concluded that the WM exhibits much more obvious mean stress relaxation behavior than BM during the fatigue life, especially at the lower applied strain amplitudes. The mean stress of WM is also negative in the whole fatigue process with an initial value 
(Eq.3, $\left.\sigma_{\mathrm{m}}\right|_{N=1}$ ) of $-35 \mathrm{MPa} \sim-15 \mathrm{MPa}$ in varies strain amplitudes. The smaller the strain amplitudes become, the larger the initial mean stress magnitudes and the stress relaxation ranges become. The different mean stress relaxation features for WM and $\mathrm{BM}$, as well as those for different strain amplitudes may be caused by the different deformation mechanisms in different materials and loading levels [42].

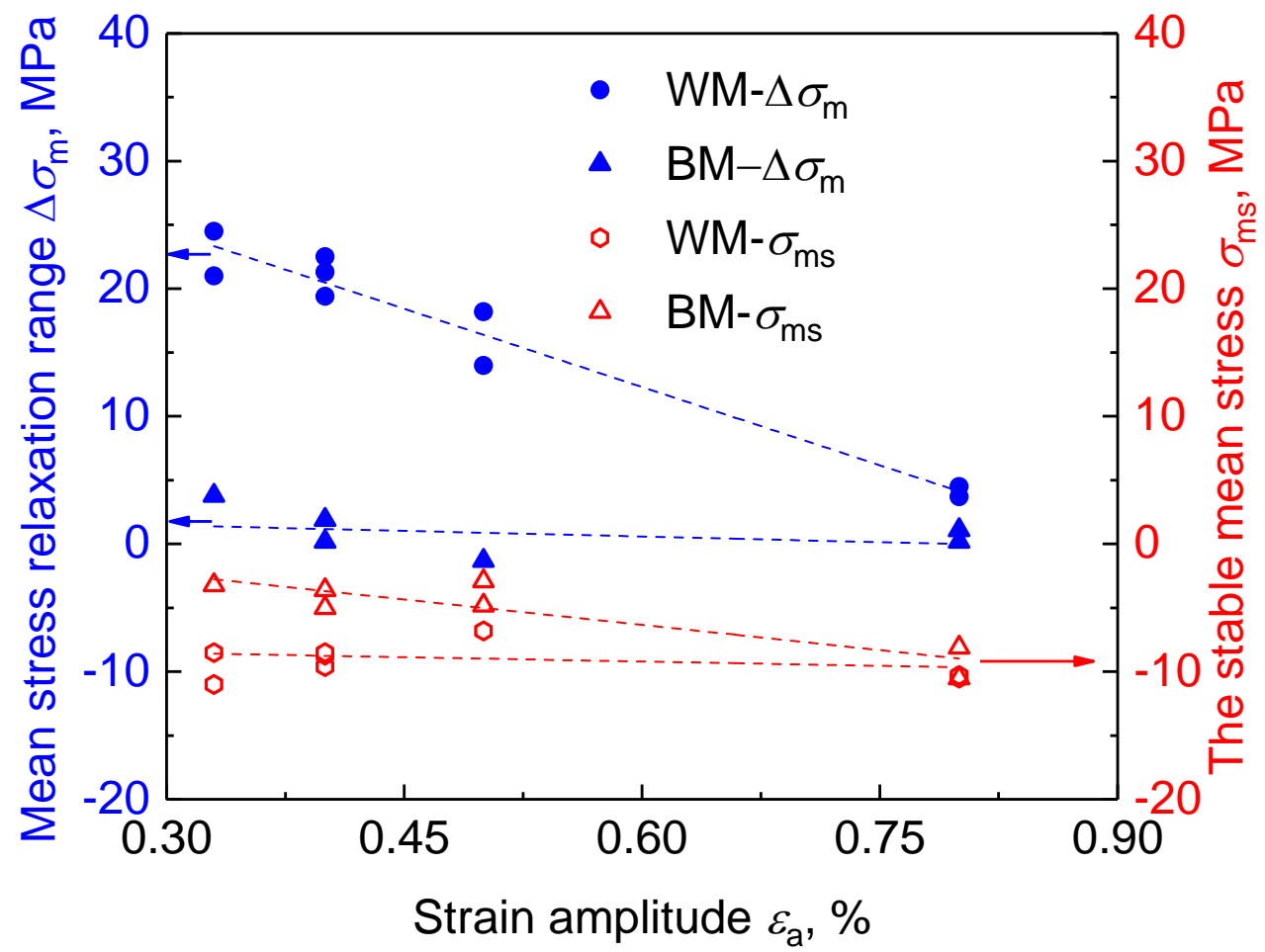

Fig. 11 The mean stress relaxation behaviors of WM and BM at different applied strain amplitude

\subsubsection{Hysteresis loops of the WM and BM}

Fig. 12(a) and (b) show the hysteresis loops of the WM and BM at the half life for the strain amplitudes of $0.3 \%, 0.33 \%, 0.4 \%, 0.5 \%$ and $0.8 \%$, respectively. The hysteresis loops for WM and BM with common compressive tips are also shown at the right sides of Fig. 12(a) and (b), in which the hysteresis loop branches fall on the doubled cyclic stress-strain curve for all strain levels [48]. Both the WM and BM exhibit Masing behavior [8,48,49]. The cyclic stress-strain curves of WM and BM is obtained by connecting the peak tips of the hysteresis loops at the half life cycle for different strain amplitudes in the corresponding figures. And the monotonic tensile stress-strain curves of WM and BM obtained from the loading conditions of $\mathrm{W} 1$ and 
B1(Table.1) are also embedded in Fig. 12(a) and (b) for comparison. Meanwhile, Fig. 13(a) and (b) show the hysteresis loops at different life periods (eg. the first cycle, the $50 \%$ life cycle, the $90 \%$ life cycle and the last cycle) for the WM and BM under the strain amplitude of $0.5 \%$, respectively. It is shown that during the fatigue process, the absolute value of peak/valley stress keep decreasing and the hysteresis loops become wider for both the WM and BM. Obvious cyclic softening is observed from the comparing of the cyclic stress-strain curves with the monotonic tensile stress-strain curves and the hysteresis loops variation for both the WM and BM. The cyclic stress-strain curves can be applied to describe the cyclic deformation behavior of the WM and BM under cyclic loadings, which can be expressed with the Ramberg-Osgood equation with the fitting values of $K$ and $n$ listed in Table 2.

Table 2 Half-life cyclic stress-strain parameters for the WM and BM.

\begin{tabular}{ccc}
\hline & $K$ & $n$ \\
\hline WM & 869 & 0.059 \\
BM & 891 & 0.071 \\
\hline
\end{tabular}

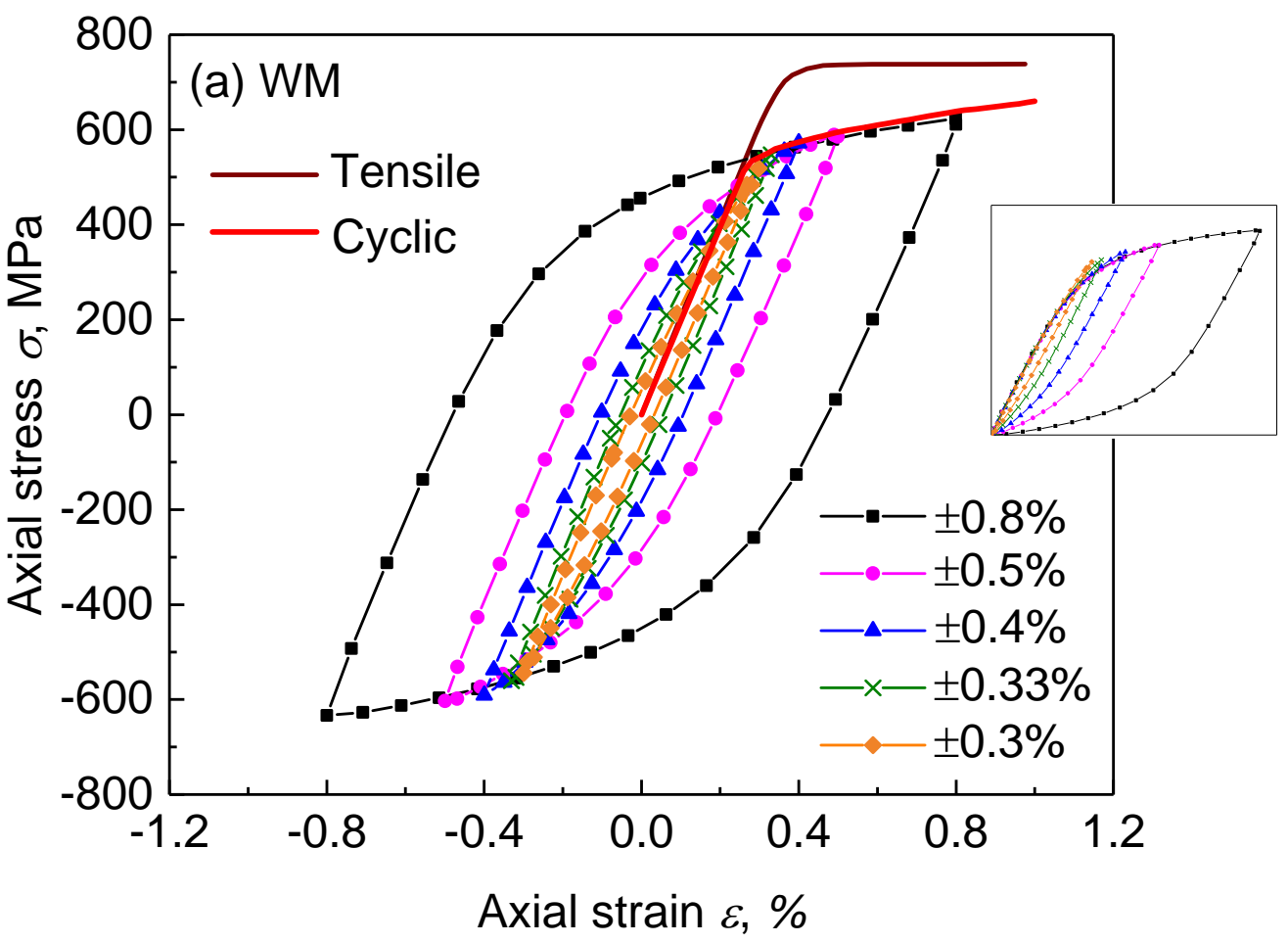




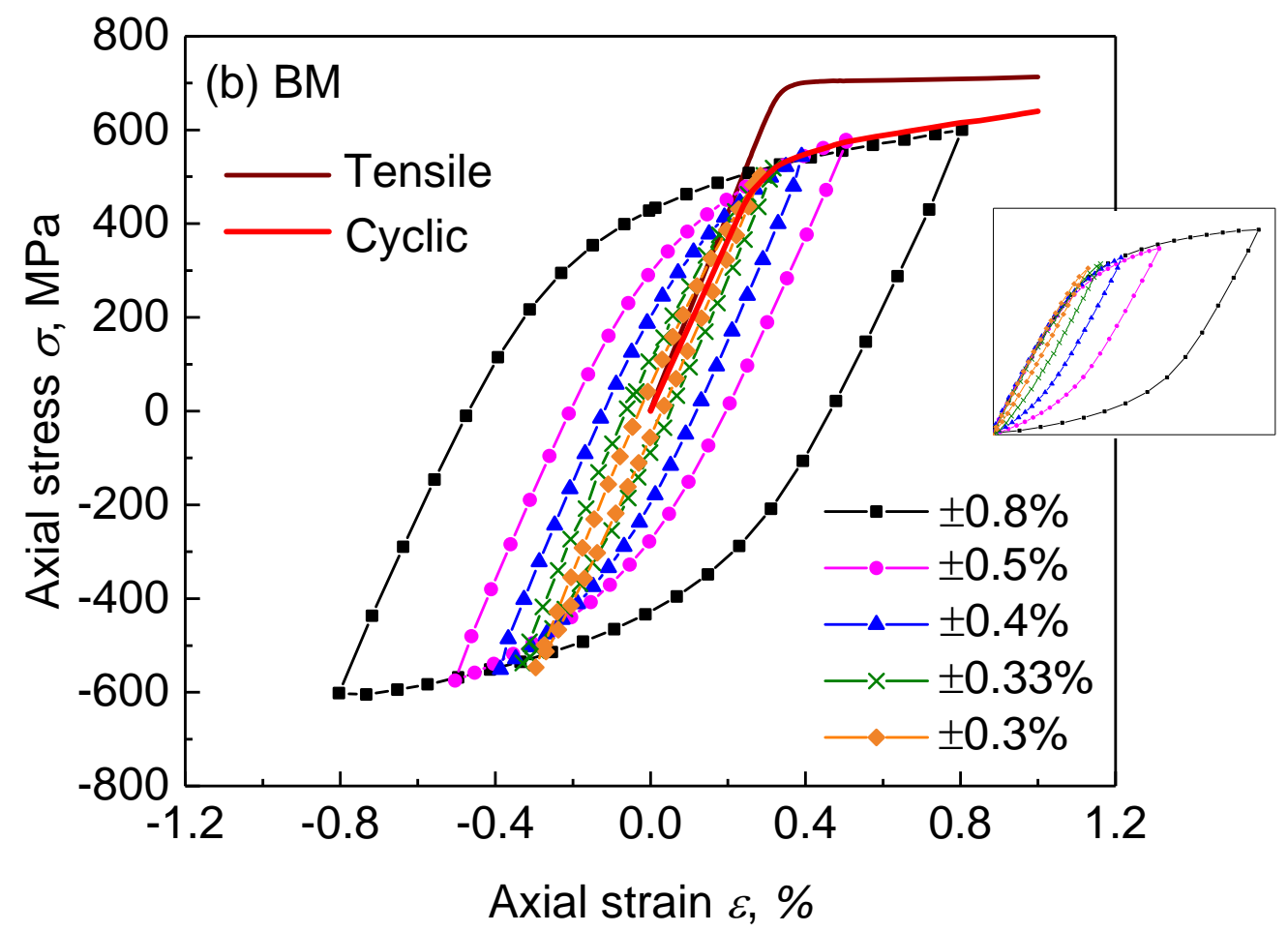

Fig. 12 The hysteresis loops at the half-life cycle and the corresponding cyclic stress-strain curves (a) weld metal (WM); (b) base metal (BM)

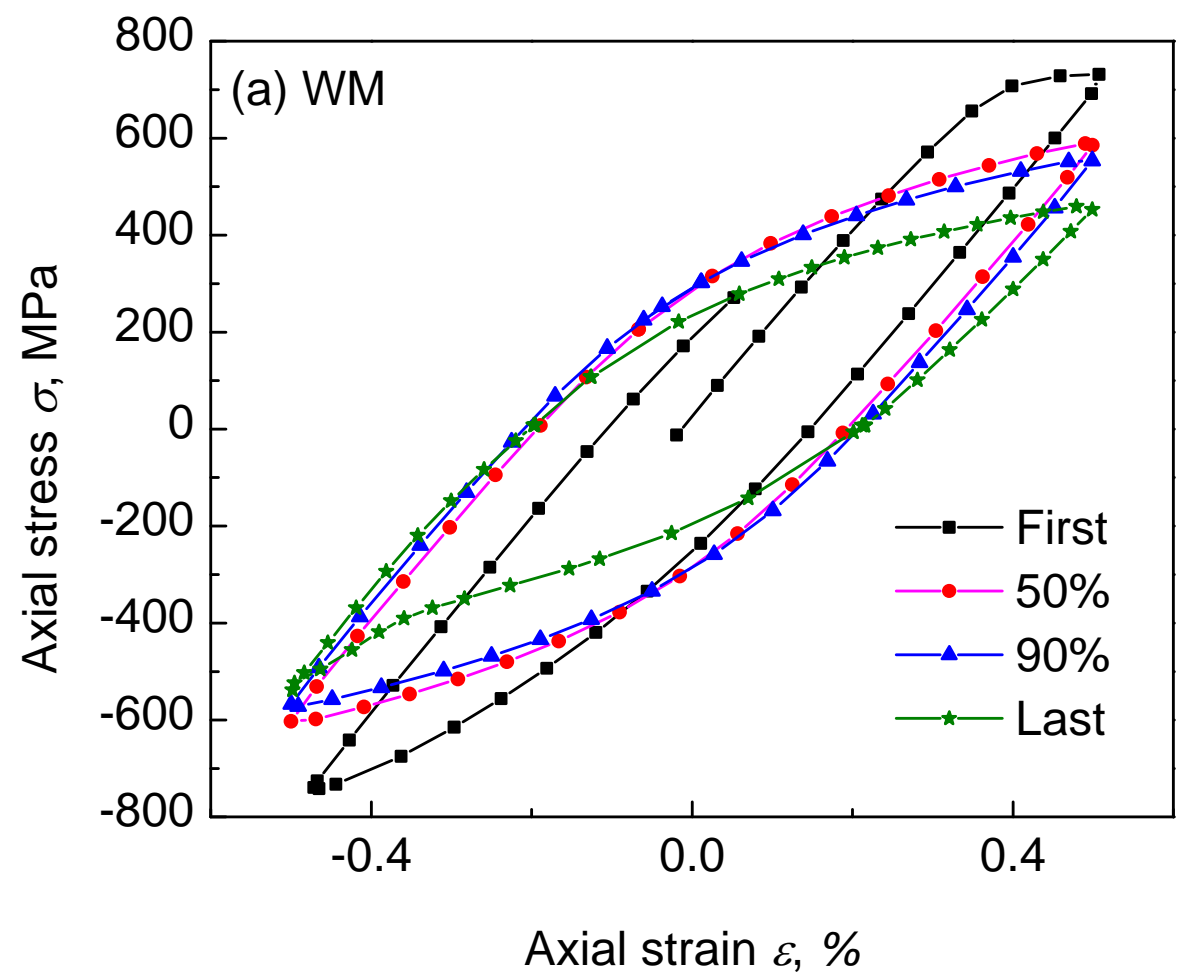




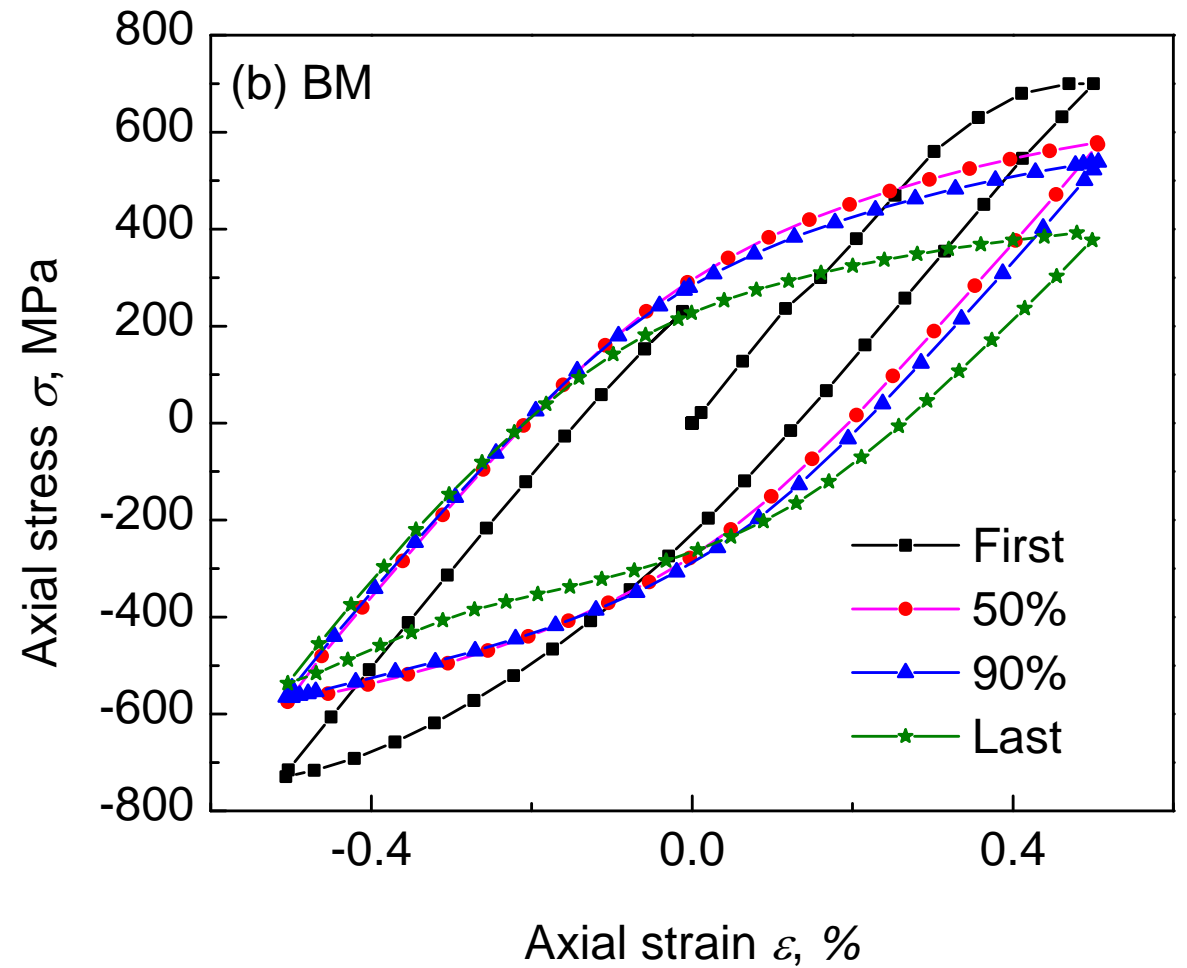

Fig. 13 The hysteresis loops from different life periods (a) weld metal (WM); (b) base metal (BM)

\subsection{The ratchetting behavior of welded joint under stress-controlled condition}

Under the stress-controlled cyclic loadings of WR1 WR5 and BR1 BR3 (Table 1), the ratchetting behavior tests of $\mathrm{WM}$ and $\mathrm{BM}$ were carried out with the stress ratio $\mathrm{R}=-1$ and various stress amplitudes. Fig. 14(a) shows the ratchetting evolution curves of WM with the stress amplitudes varying from $618 \mathrm{MPa}$ to $735 \mathrm{MPa}$. Fig. 14(b) displays the ratchetting evolution curves of $\mathrm{WM}$ and $\mathrm{BM}$ at the stress amplitudes of $618 \mathrm{MPa}, 625 \mathrm{MPa}$ and $650 \mathrm{MPa}$, respectively. Similar with section 3.2, the horizontal axis in Fig. 14 represents the number of cycles normalized by the final failure cycles. It can be concluded from Fig. 14(a) and (b) that significant ratchetting deformation occur along the tensile direction in both the WM and BM under the stress-controlled cyclic loadings with zero mean stress $(\mathrm{R}=-1)$, which does not conform with the conventional $J_{2}$-based plasticity. Similar phenomenon has also been reported for the 9-12\% $\mathrm{Cr}$ steel in the works of $\mathrm{Wu}$ et al. [42] and Yaguchi et al. [50], which is attributed to the tension-compression asymmetry of the selected materials. In this work, the WM and BM were also verified to exhibit somewhat tension-compression 
asymmetry behavior corresponding to the negative mean stress (Fig. 11) with the fully reversed strain cyclic loadings. It's worth noting that the stable mean stress of WM and BM shown in Fig. 11 is as small as $-10 \sim 0 \mathrm{MPa}$, which is slight different between the tension and compression stress-strain response leading to significant ratchetting accumulation for the cyclic softening material. Further, as typical cyclic softening material, the ratchetting strain evolution curves of WM and BM can be divided into two stages: stage I is from the beginning cycle to about the $50 \sim 80 \%$ life cycle, during which the ratchetting strain accumulates slowly; stage II covers the remaining life of the corresponding loading conditions, in which the ratchetting strain increases sharply due to the ductile failure. It can also be seen from Fig. 14(a) and (b) that: (1) the ratchetting strain at a higher stress amplitude is obviously higher than that at a lower one for both the WM and BM; (2) under the same stress amplitude, the BM exhibits higher ratchetting strain than the WM does, except for the loading condition with a stress amplitude of $618 \mathrm{MPa}$ for which the ratchetting strain in WM exceeds that in the BM after the first 50\% cyclic cycles. In addition, the evolution curves of the ratcheting strain vs. actual number of cycles of WM and BM under the stress amplitudes of $618 \mathrm{MPa}, 625 \mathrm{MPa}$ and $650 \mathrm{MPa}$ are also shown in Fig. 14 (b). It can be found that although the ratchetting strain in BM is higher than that in WM at most cycles during the lifetime under each loading condition, the ratchetting strain in WM overtook that in the BM suddenly in the last several cycles due to the premature failure. The reason for this may be traced to the unstable microstructure of WM induced by the thermal welding, leading to a premature microstructure collapse in the ratchetting deformation process. To support this conjecture, Fig.15 (a) and (b) show the microstructures of the BM and WM in the as-received conditions characterized by TEM [51], Fig.15 (c) and (d) shows the local inclusions in the BM and WM characterized by SEM after the ratchetting tests, respectively. It can be seen that the WM exhibits much more unstable microstructure than the BM. It also shows that the inclusions in the BM are planar and embedded in the matrix, while the inclusions in the WM are three-dimensional welding pores which are more critical. Despite the accelerated ratchetting deformation process (Fig. 14), the cyclic softening behavior of 
the $\mathrm{WM}$ and $\mathrm{BM}$ can also be reflected by the area change covered by the hysteresis loops and the evolution of the strain amplitude response in the stress-controlled cyclic tests. Fig. 16 shows the evolution process of stress-strain hysteresis loops of WM and $\mathrm{BM}$ at different life stages (eg. the first cycle and the 30\% 97\% life stages) for the stress amplitude of $650 \mathrm{MPa}$. Fig. 17 shows the strain amplitude response evolution curves of WM and BM with various applied stress amplitudes. It can be seen from the figures that although the stress-strain hysteresis loop is quite narrow at the beginning of cyclic tests, the areas covered by stress-strain hysteresis loops for both the WM and BM become larger and larger during the further cyclic loadings. The stress-strain hysteresis loops exhibit an accelerating forward trend due to the cyclic softening and ratchetting damage. For all the loading conditions of WR1 WR5 and BR1 BR3, the strain amplitude responses of WM and BM are increase with the increasing of stress amplitudes and loading cycles. In addition the strain amplitude of BM is higher than that of WM at the same stress level (Fig. 17).

In order to investigate the effect of stress ratio $\mathrm{R}$ on the ratchetting strain evolution, the stress-controlled ratcheting tests under the loading conditions of WR6-WR10 (Table1) were carried out on the WM, in which the peak stress was adopted as $625 \mathrm{MPa}$, and the valley stress varied from $-655 \mathrm{MPa}$ to $-500 \mathrm{MPa}$ for different stress ratios of $-0.8,-0.88,-1,-1.02,-1.03$ and -1.05 . The average ratchetting strain rate $\underset{r}{\mathrm{~K}}$ is defined to analyse the ratchetting behavior of WM under loading conditions with various R. It is found from the ratchetting experiments of WM that the rapid ratchetting deformation happens when the ratchetting strain reaches $0.4 \%$ for most cases due to the cyclic damage (Fig. 14). It costs the WM over 90\% lifetime to reach the total ratchetting strain magnitude of $0.4 \%$ for all the loading conditions. The average ratchetting strain rate $\underset{r}{\mathbb{\&}}$ can be defined as

$$
\underset{r}{\&}=\frac{0.4 \%}{\left.N\right|_{\varepsilon_{r}=0.4 \%}}
$$

where $\left.N\right|_{\varepsilon_{r}=0.4 \%}$ is the cyclic cycles corresponding to the ratchetting strain magnitude 
of $0.4 \%$, and $1 / \&_{r}$ can reflect the magnitude of fatigue life for $\mathrm{WM}$ in the cyclic ratchetting tests. Fig. 18 shows the relationship between average ratchetting strain rate \& and stress ratio $\mathrm{R}$, in which WM exhibit the largest average ratchetting strain rate $\underset{r}{\&}(\mathrm{R}=-1)$ comparing with the other loadings with stress ratio of $-0.8,-0.88,-1.02$, -1.03 and -1.05 at the same peak stress level. When $\mathrm{R}$ ratio is larger than than $-1, \underset{r}{\mathrm{\&}}$ decreases with the increasing of stress ratio, resulting in a longer fatigue life. When $\mathrm{R}$ ratio declines in the range smaller than -1 , $\underset{r}{\&}$ keeps decreasing and accompanies with longer fatigue life. It is worth noting that even when $\mathrm{R}$ ratio was -1.02 and -1.03 , the WM still exhibit ratchetting deformation at the tensile direction, while the ratcheting deformation changes to the compressive direction when $\mathrm{R}$ ratio is equal to -1.05 or smaller.

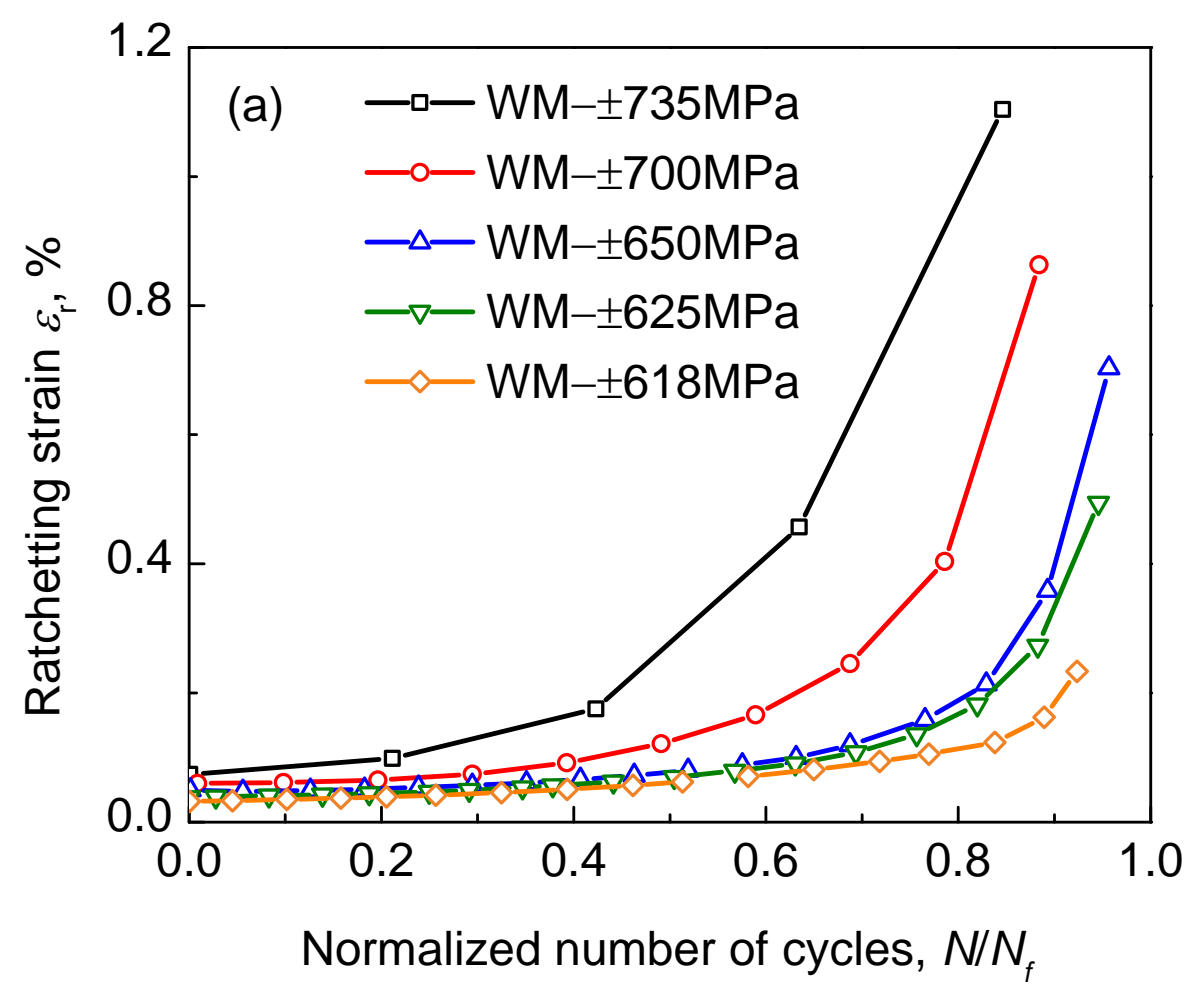




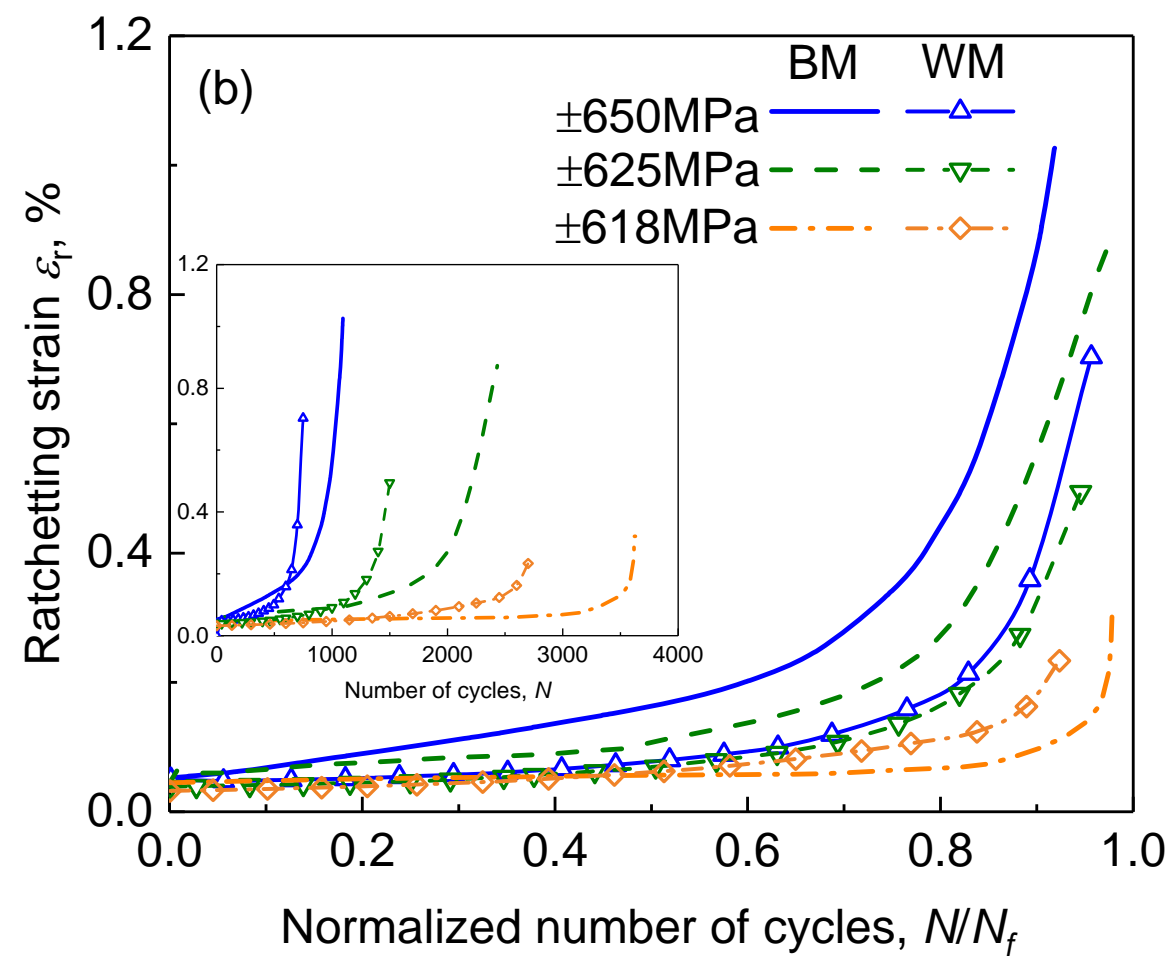

Fig. 14 The ratchetting strain evolution curves: (a) weld metal (WM); (b) weld metal (WM) and base metal(BM)
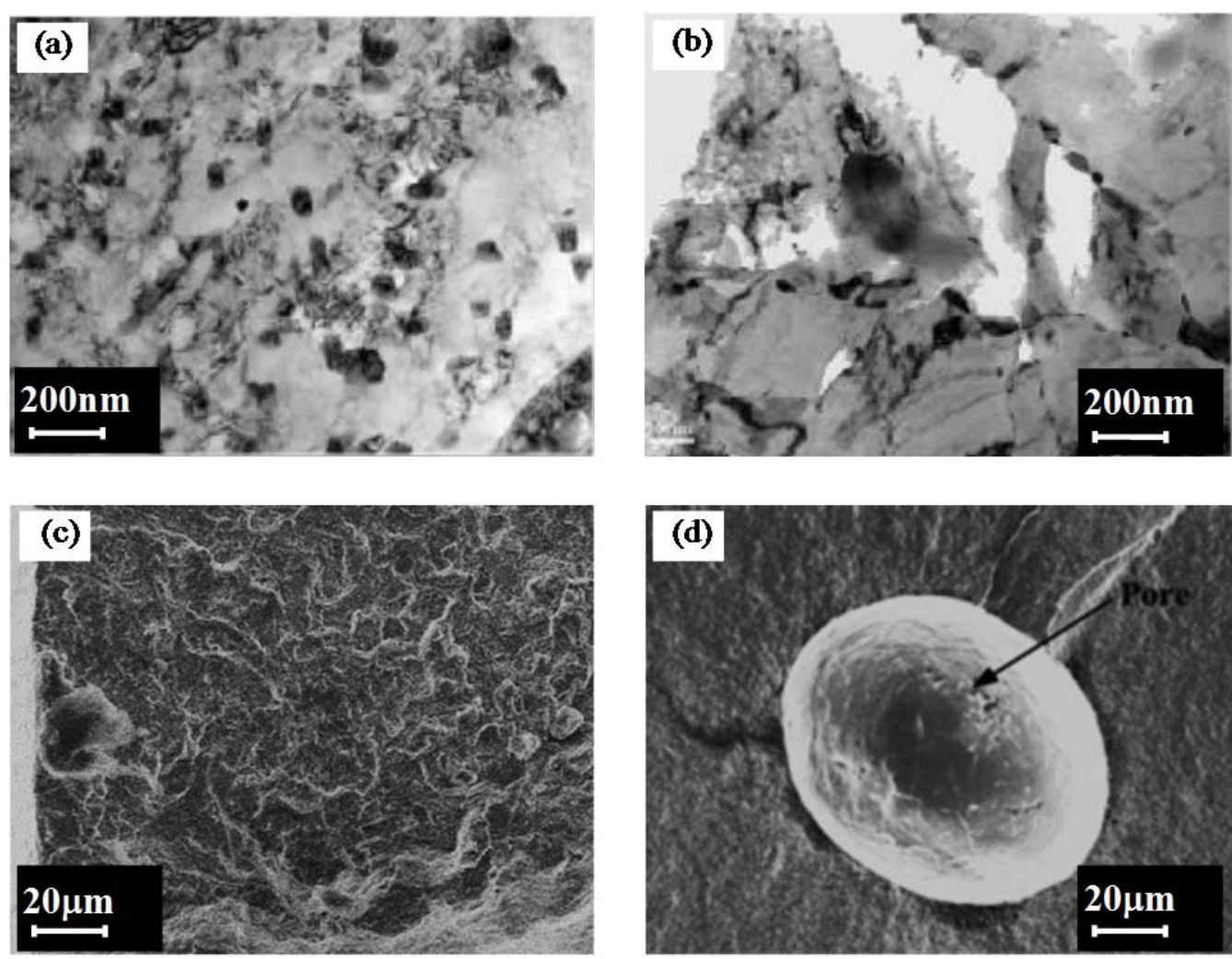

Fig. 15 Microstructure and inclusion morphology in the BM and WM: (a) the as-received BM; (b) the as-received WM; (c) inclusion in the BM; (d) inclusion in the WM 


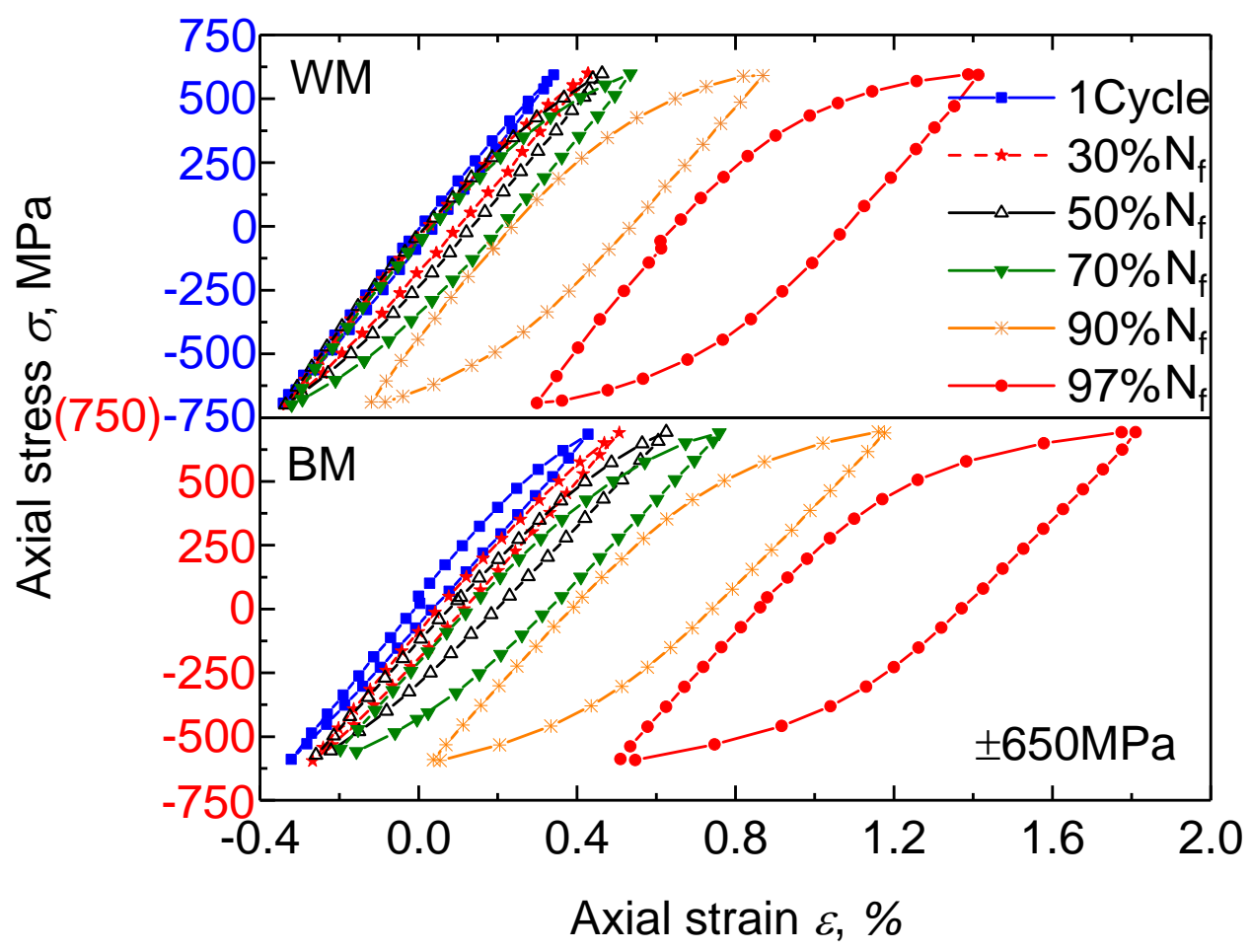

Fig. 16 The evolution of stress-strain hysteresis loops of WM and BM

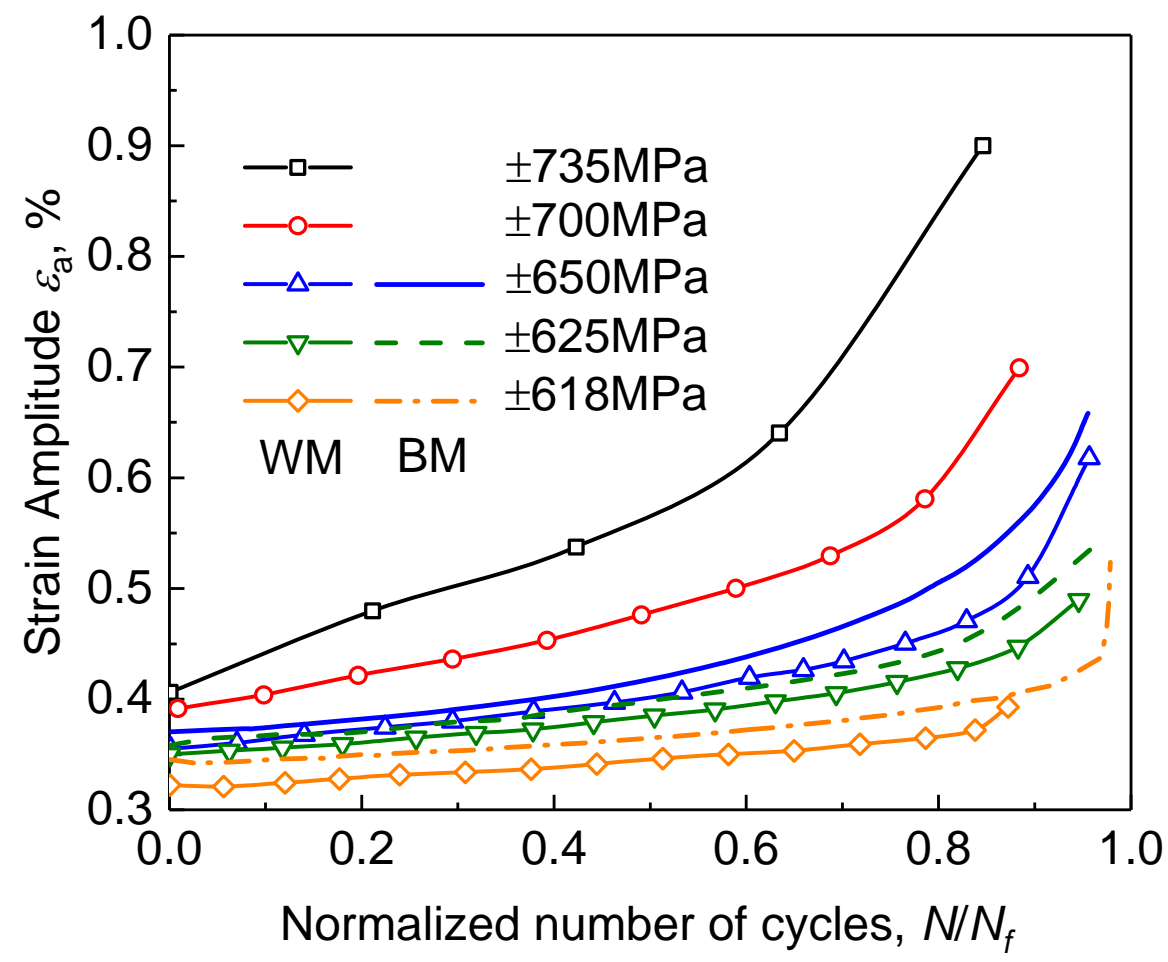

Fig. 17 The evolution curve of strain amplitudes of WM and BM 


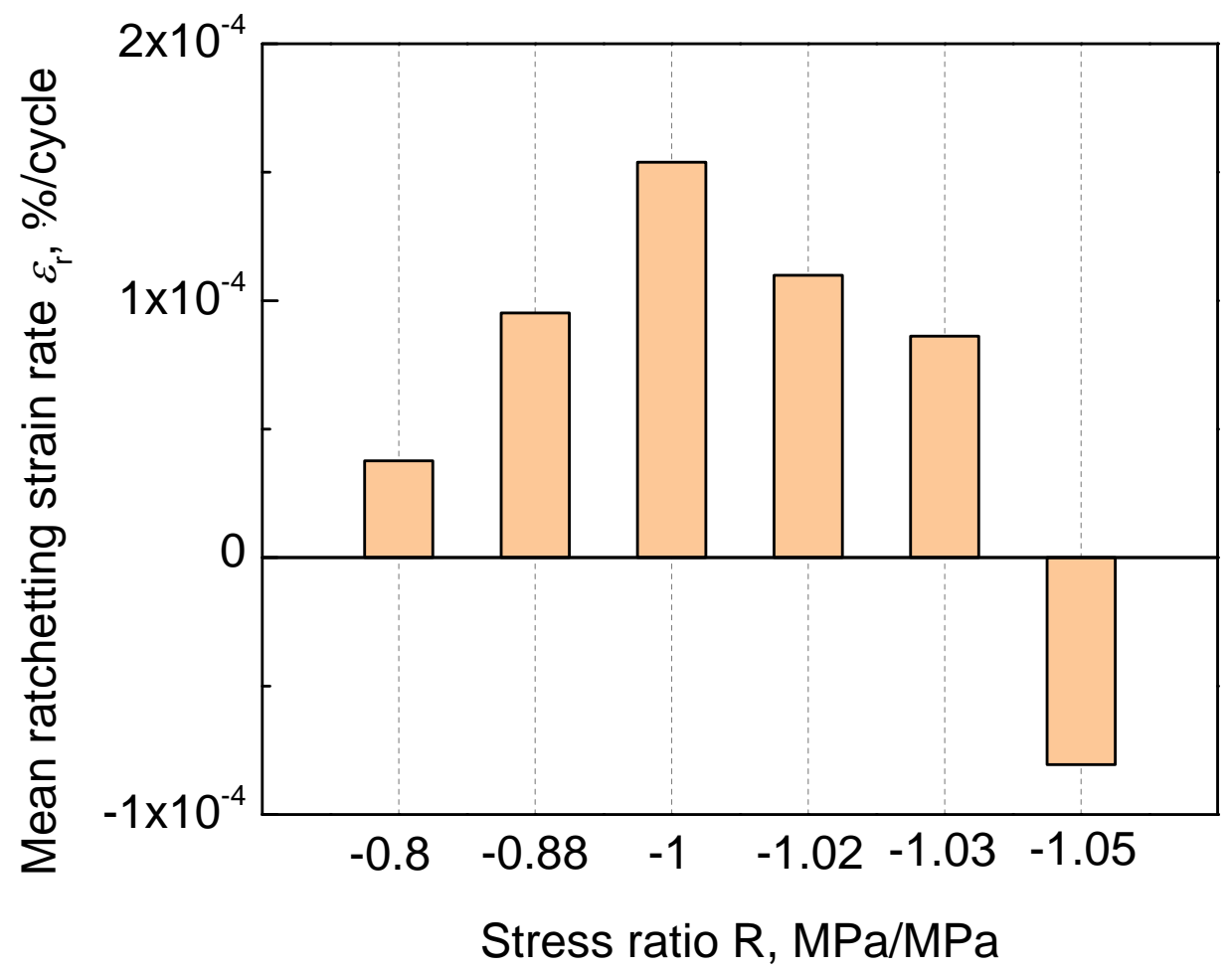

Fig. 18 The relationship between average ratchetting strain rate and stress ratio R for WM

\subsection{The fatigue life of WM and BM under strain and stress loading conditions}

The fatigue curves of total strain amplitude $\varepsilon_{a}$ versus reversed cycles to failure $2 N_{\mathrm{f}}$ of $\mathrm{WM}$ and $\mathrm{BM}$ under the strain (stress)-controlled cyclic loadings are shown in Fig. 19. All total strain amplitudes are obtained at half life cycle. Both WM and BM show similar trend of increasing fatigue life with decreasing of strain amplitude, and significant lifetime difference between the stress and strain control modes can be detected. At the same half-life strain amplitude, the fatigue lives of WM and BM under strain-controlled mode are much longer than that under the stress control mode. Retrospect to Section 3.3, the difference between the fatigue behavior of WM or BM under the strain and stress control modes can be related to the influence of tension-compression asymmetry [42]. For the strain-controlled cyclic tests, the fatigue failure is mainly caused by the micro crack initiation and propagation, which is scarcely influenced by the small mean stress induced by the slight cyclic asymmetry. However, the failure mechanism of materials under the stress-controlled test is the ratchetting damage, which is easily actuated by the mean strain response caused by 
the tension-compression asymmetry, especially for the stress conditions with zero mean stress $(\mathrm{R}=-1)$. In addition, it can be seen in Fig. 19 that the BM possesses higher fatigue strength than the WM for both the strain and stress-controlled modes, the fatigue life of the BM is about twice over that of the WM at the same strain amplitude. The reason for the reduction of fatigue strength in WM comparing with the $\mathrm{BM}$ is mainly focused on the microstructure weakening caused by the thermal welding.

\subsection{The failure behavior and failure location shift in the welded joint}

After the above-mentioned strain and stress-controlled cyclic tests, the failure locations for all the WM specimens consisting of the WM, BM and HAZ (as shown in Fig. 4) were observed and recorded. The results show that the failure locations in the WM specimens during strain-controlled cyclic loadings are shifting with the changing of the applied loading levels. Fig. 20(a) displays the statistical diagram of failure locations of the WM specimens under the strain-controlled tests with various strain amplitudes. It is shown that the specimens always fracture at the center of WM (location A) when the applied strain amplitude is higher $(0.8 \%)$, and the failure locations shift to BM at the region nearby HAZ (location B) when the lower strain amplitudes of $0.3 \%$ and $0.33 \%$ are applied. For the intermediate strain amplitudes of $0.5 \%$ and $0.4 \%$, the specimens failed stochastically at location $\mathrm{A}$ or location $\mathrm{B}$. However, for the stress-controlled loading conditions, the WM specimens always failed at the WM center (location A) accompanied with necking failure. Furthermore, SEM observations were carried out on the fracture surface of representative WM specimens under the strain-controlled loadings, the most common failure initiation sites for the specimens failed at location B and location A were presented in Fig. 20(b) (c) and Fig. 20(d) (f), respectively. It can be concluded that the failure

initiation for the WM specimens fracturing at location B is mainly induced by the aggregate inclusion defects generated by the thermal welding (Fig. 20(b) (c)), while the major infant failures in location A were produced by micro crack initiation and single inclusion defects (Fig. 20(d) (f)). 


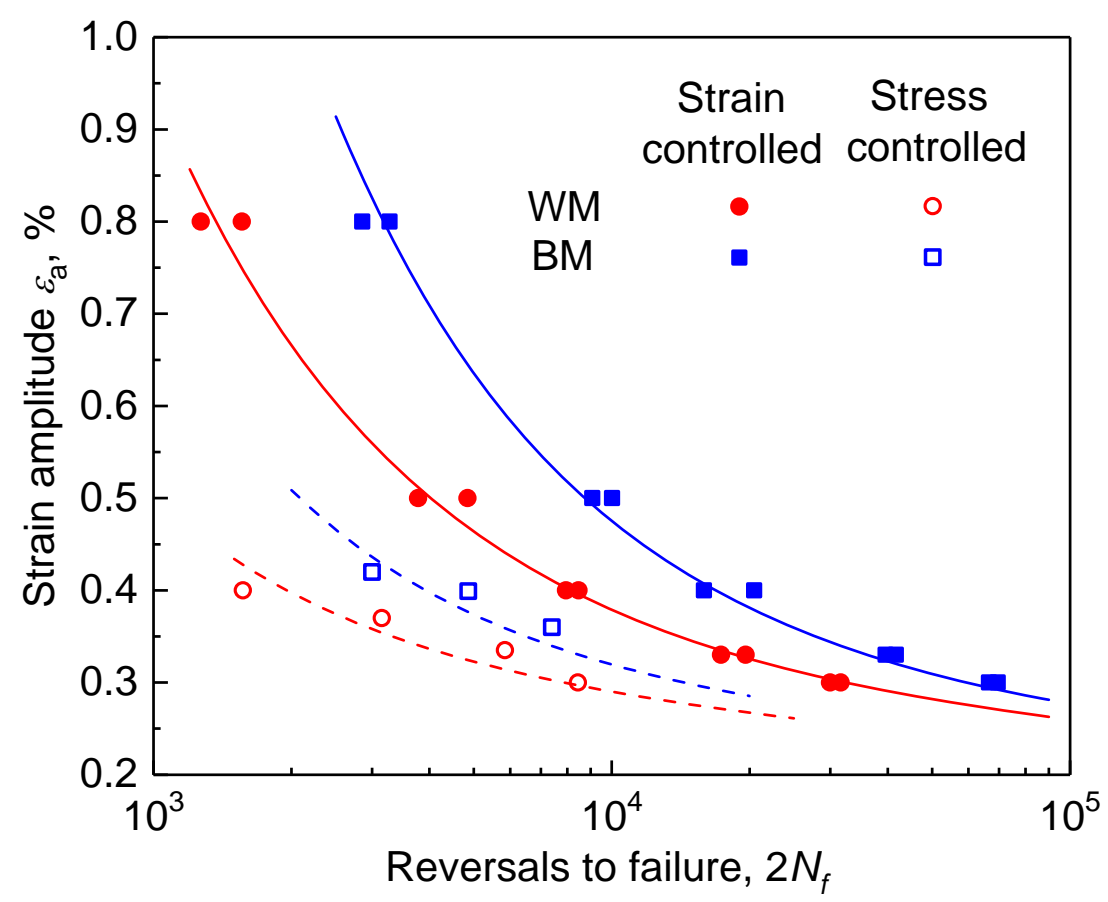

Fig. 19 Strain amplitude vs. number of reversals to failure for the WM and BM

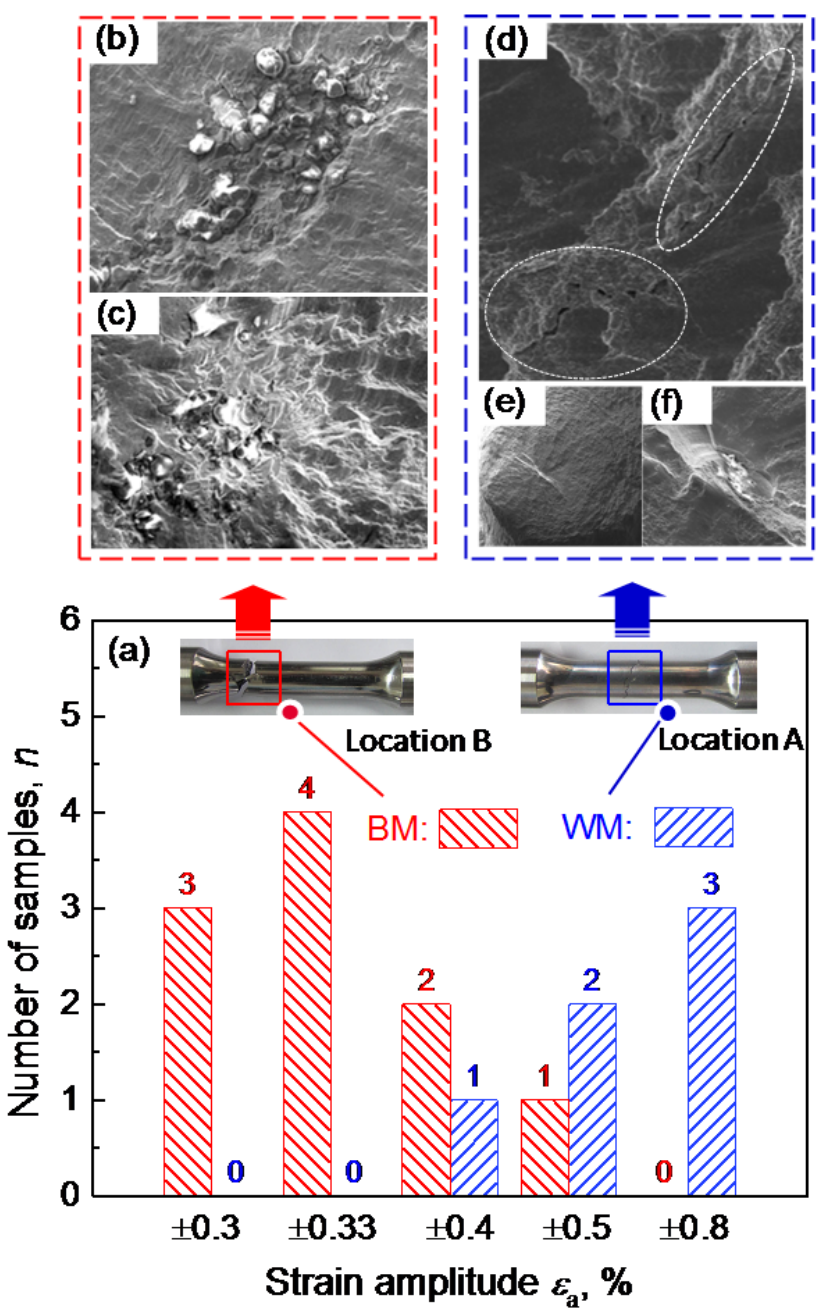

Fig. 20 Failure behavior and failure location observation and statistics for the WM specimens 


\subsection{Analysis for failure location shift behavior for the WM specimens by FEM method}

The half-life cyclic deformation behavior of the WM specimens is simulated by employing the finite element mesh presented in Fig. 4 with the cyclic strain loading of $\pm 0.8 \%, \pm 0.5 \%, \pm 0.4 \%, \pm 0.33 \%$ and $\pm 0.3 \%$, respectively. Since the equivalent plastic strain amplitude is an important influence factor for the LCF life, the distribution contours of equivalent plastic strain amplitude $\Delta \varepsilon_{\text {epa }}$ for the WM specimens at various applied strain amplitudes are extracted from the ABAQUS simulations and shown in Fig. 21. Meanwhile, the evolution curve of equivalent plastic strain amplitude difference between the location A and B (as shown in Fig. 21, $\left.\left.\Delta \varepsilon_{\text {epa }}\right|_{\text {location A }}-\left.\Delta \varepsilon_{\text {epa }}\right|_{\text {location B }}\right)$ vs. the strain amplitude is plotted in Fig. 22. The equivalent plastic strain amplitude distribution along the red imaginary line (shown in Fig. 21) across the most critical points in the welded joint are also presented in Fig. 22 for various strain amplitudes. It can be concluded from Fig. 21 and Fig. 22 that the equivalent plastic strain amplitude distributions in the WM specimens are heterogeneous and vary with the changing of applied strain amplitude due to different mechanical features in the WM, BM and HAZ. The shifting behavior of maximum equivalent plastic strain amplitude location in the welded joint can be taken as the explanation for the failure location shifting behavior of the WM specimens, as recorded in Fig. 20. For the lower applied strain amplitudes $(0.3 \%$ and $0.33 \%)$, the maximum equivalent plastic strain amplitude is found at location $\mathrm{B}$, which are much higher than those at location A due to the local stress concentration (Fig. 21 (a) (b) and Fig. 22 (a)). In this viewpoint, the WM specimens failed at location B for the most severe plastic damage. The equivalent plastic strain amplitude at location A is increased with the increasing of applied strain amplitudes. When the applied strain amplitudes reach intermediate level of $0.4 \%$ and $0.5 \%$, comparable equivalent plastic strain amplitude is found at location A and B (Fig. 21 (c) (d) and Fig. 22 (b)), then the specimens failed stochastically at location A or location B, which may be influenced by the random microstructure defects. Finally, when the strain amplitude becomes $0.8 \%$, maximum equivalent plastic strain amplitude in the WM specimen 


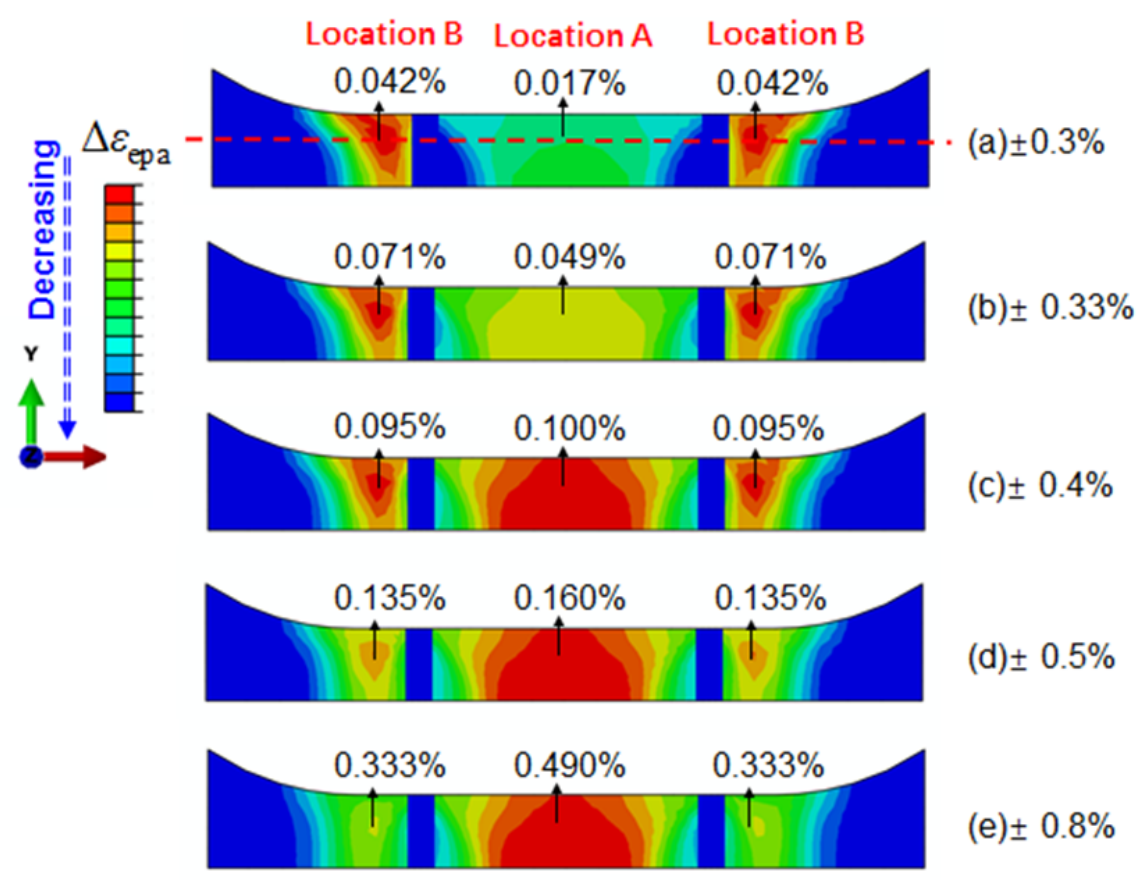

Fig. 21 The equivalent plastic strain amplitude distribution contours for the WM specimens at various applied strain amplitudes

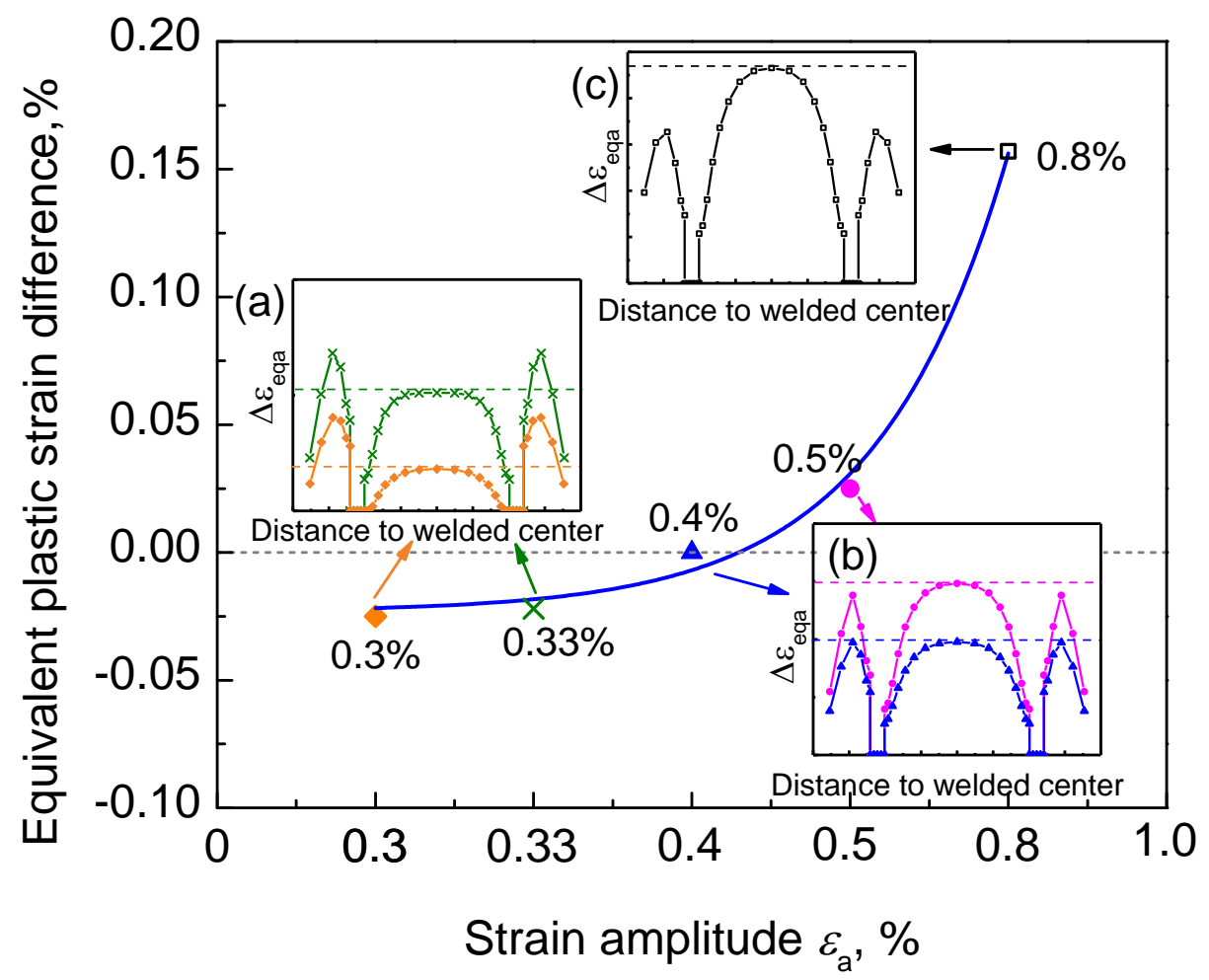

Fig. 22 The equivalent plastic strain amplitude distribution along dinger line in the WM specimens at various applied strain amplitudes

shifts to location A, with a much higher value than that at location B (Fig. 21 (e) and Fig. 22 (c)). The specimen is then failed at location A due to the large plastic damage. 
Generally speaking, the maximum equivalent plastic strain amplitude location is in step with the failure locations in the WM specimens for all the strain levels. Still and all, the inducement factors of material failure in the WM specimen are more than the local equivalent plastic strain amplitude, which also include the local microstructure feature, local equivalent stress amplitude and the local mechanical inhomogeneity in the welded area $[8,13]$. The accurate life prediction for the welded specimen should also consider the influence of local stress concentration factor, the local stress triaxiality, and so on [52]. Furthermore, it should be mentioned that as the preliminary exploration of the fatigue failure behavior simulations for the welded joint, there also has some problems that need further effort. Firstly, the HAZ was treaded as elastic material in the simulations due to its extremely higher hardness and yield stress in this section. However, due to the influence of the thermal welding process, the boundary locations in the HAZ nearby the WM or BM have the similar yield stress to the WM or BM. This phenomenon may lead to some degree of stress concentrations and strain localisation within the HAZ, which should be concerned in the future studies. Secondly, the residual stresses in welded joint are neglected in this work in consideration of the $20 \mathrm{~h}$ post weld heat treatment for residual stress reducing and the cyclic stress-strain relations employed in the simulations, with which the effect of residual stress is contained to some extent. The research work for more comprehensive explanation and prediction for the failure location shift and low cycle fatigue behaviors of the WM specimen based on the fatigue damage method is in progress, which will be introduced in the future works.

\section{Conclusions}

In this paper, the low cycle fatigue (LCF) and ratchetting behavior of the base metal (BM) and weld metal (WM) for NiCrMoV steel welded joint were carried out under the strain and stress-controlled cyclic loadings at room temperature. The main findings are summarized as follows: 
(1) Both WM and BM exhibit a significant strain-level-dependent cyclic softening over the lifetime under the strain-controlled fatigue. Comparatively, a higher fatigue strength is obtained in BM than in WM. Compared to the BM, a higher softening rate was observed in WM.

(2) In the stress-controlled cyclic tests, a significant ratchetting occurs along the tensile direction in both the WM and BM even under the fully reversed condition $(\mathrm{R}=-1)$ due to the slight tension-compression asymmetry. By contrast, the BM exhibit larger ratchetting deformation but longer fatigue life than the WM under the same stress amplitude.

(3) Under the strain-controlled fatigue, the failure location in the WM specimens shifts from BM region (nearby the heat affected zone) to the center of WM while the strain amplitude increasing. The finite element simulation results for the half-life cyclic deformation behavior of the WM specimens shows that the maximum equivalent plastic strain amplitude location is in step with the failure location in the WM specimen for all the strain levels.

\section{Acknowledgements}

The authors are grateful for the supports provided by the National Natural Science Foundation of China $(11872181,11302079)$ and Shanghai natural science foundation (18ZR1408900).

\section{References}

[1] Pham TH, Kim SE. Microstructure evolution and mechanical properties changes in the weld zone of a structural steel during low-cycle fatigue studied using instrumented indentation testing. Int J Mech Sci 2016; 114: 141-56.

[2] Cheng GX, Kuang ZB, Lou ZW, Li H. Experimental investigation of fatigue behaviour for welded joint with mechanical heterogeneity. Int J Pres V Pip 1996; 61: $229-42$. 
[3] Wang SQ, Li WY, Zhou Y, Li X, Chen DL. Tensile and fatigue behavior of electron beam welded dissimilar joints of Ti-6Al-4V and IMI834 titanium alloys. Mater Sci Eng A 2016; 649: 146-52.

[4] Kima SJ, Choia PH, Dewaa RT, Kimb WG, Kimb MH. Low cycle fatigue properties of Alloy 617 base metal and weld joint at room temperature. Proc Mater Sci 2014; 3: 2201-6.

[5] Wang H, Jing HY, Zhao L, Han YD, Lv XQ, Xua LY. Dislocation structure evolution in 304L stainless steel and weld joint during cyclic plastic deformation. Mater Sci Eng A 2017; 690: 16-31.

[6] Wen GD, Ma TJ, Li WY, Li JL, Guo HZ, Chen DL. Cyclic deformation behavior of linear friction welded Ti6A14V joints. Mater Sci Eng A 2014; 597: 408-14.

[7] Shankar V, Sandhya R, Mathew MD. Creep-fatigue-oxidation interaction in Grade 91 steel weld joints for high temperature applications. Mater Sci Eng A 2011; 528: 8428-37.

[8] Veerababu J, Goyal S, Sandhya R, Laha K. Low cycle fatigue behaviour of Grade 92 steel weld joints. Int J Fatigue 2017; 105: 60-70.

[9] Feng AH, Chen DL, Ma ZY. Microstructure and cyclic deformation behavior of a friction-stir-welded 7075 Al alloy. Metall Mater Trans A 2010; 41: 957-71.

[10] Wang SQ, Liu JH, Lu ZX, Chen DL. Cyclic deformation of dissimilar welded joints between Ti-6Al-4V and Ti17 alloys: Effect of strain ratio. Mater Sci Eng A 2014; 598: 122-34.

[11] Wang SQ, Liu JH, Chen DL. Strain-controlled fatigue properties of dissimilar welded joints between Ti-6Al-4V and Ti17 alloys. Mater Design 2013; 49: 716-27.

[12] Wang SQ, Liu JH, Chen DL. Tensile and fatigue properties of electron beam welded dissimilar joints between Ti-6Al-4V and BT9 titanium alloys. Mater Sci Eng A 2013; 584: 47-56.

[13] Wang XF, Shao CD, Liu X, Lua FG. Transition and fracture shift behavior in LCF test of dissimilar welded joint at elevated temperature. J Mater Sci Tech 2018; 34: $720-31$. 
[14] Cavaliere P, Panella F. Effect of tool position on the fatigue properties of dissimilar 2024-7075 sheets joined by friction stir welding. J Mater Process Tech 2008; 206: 249-55.

[15] Gaur V, Enok Mi, Okada T, Yomogida S. A study on fatigue behavior of MIG-welded Al-Mg alloy with different filler-wire materials under mean stress. Int J Fatigue 2018; 107: 119-29.

[16] Schijve J. Fatigue predictions of welded joints and the effective notch stress concept. Int J Fatigue 2012; 45: 31-8.

[17] Li M, Barrett RA, Scully S, Harrison NM, Leen SB. Cyclic plasticity of welded P91 material for simple and complex power plant connections. Int J Fatigue 2016; 87: 391-404.

[18] Chen J, Xia Z. A fatigue life prediction method for coke drum base, weld, and HAZ materials from tensile properties. Mater Design 2014; 63: 575-83.

[19] Farragher TP, Scully S, O’Dowd NP, Hyde CJ, Leen SB. High temperature, low cycle fatigue characterization of P91 weld and heat affected zone material. J Press Vess T ASME 2014; 136: 021403-1.

[20] Zhang QB, Zhang JX, Zhao PF, H Y, Yu ZH, Fang XY. Low-cycle fatigue behaviors of a new type of $10 \% \mathrm{Cr}$ martensitic steel and welded joint with Ni-based weld metal. Int J Fatigue 2016; 88: 78-87.

[21] Luo HL, Kang GZ, Kan QH, Huang Y. Experimental investigation on the heterogeneous ratchetting of SUS301L stainless steel butt weld joint during uniaxial cyclic loading. Int J Fatigue 2017; 105: 169-79.

[22] Wu DL, Zhao P, Wang QQ, Xuan FZ. Cyclic behavior of 9-12\% Cr steel under different control modes in low cycle regime: A comparative study. Int J Fatigue 2015; 70: 114-22.

[23] Ahlström J, Karlsson B. Fatigue behavior of rail steel-a comparison between strain and stress controlled loading. Wear 2005; 258:1187-93.

[24] Hasegawa S, Tsuchida Y, Yano H, Matsui M. Evaluation of low cycle fatigue life in AZ31 magnesium alloy. Int J Fatigue 2007; 29:1839-45.

[25] Shiozawa K, Kitajima J, Kaminashi T, Murai T, Takahashi T. Low-cycle fatigue 
deformation behavior and evaluation of fatigue life on extruded magnesium alloys. Proc Eng 2011; 10:1244-9.

[26] Wang H, Jing HY, Zhao L, Han YD, Lv XQ, Xu LY. Uniaxial ratcheting behaviour of 304L stainless steel and ER308L weld joints. Mater Sci Eng A 2017; 708: $21-42$.

[27] Corigliano P, Epasto G, Guglielmino E, Risitano G. Fatigue analysis of marine welded joints by means of DIC and IR images during static and fatigue tests. Eng Fract Mech 2017; 183: 26-38.

[28] Zhu ML, Xuan FZ. Effect of microstructure on strain hardening and strength distributions along a Cr-Ni-Mo-V steel welded joint. Mater Design 2015; 65: 707-15.

[29] Zhu ML, Wang DQ, Xuan FZ. Effect of long-term aging on microstructure and local behavior in the heat-affected zone of a Ni-Cr-Mo-V steel welded joint. Mater Charact 2014; 87: 45-61.

[30] Zhu ML, Liu LL, Xuan FZ. Effect of frequency on very high cycle fatigue behavior of a low strength Cr-Ni-Mo-V steel welded joint. Int J Fatigue 2015; 77: 166-73.

[31] Luo LH, Huang YH, Xuan FZ. Deflection behaviour of corrosion crack growth in the heat affected zone of CrNiMoV steel welded joint. Corros Sci 2017; 121: $11-21$.

[32] Luo LH, Huang YH, Weng S, Xuan FZ. Mechanism-related modelling of pit evaluation in the $\mathrm{CrNiMoV}$ steel in simulated environment of low pressure nuclear steam turbine. Mater Design 2016; 105: 240-50.

[33] Du YN, Zhu ML, Xuan FZ. Transitional behavior of fatigue crack growth in welded joint of 25Cr2Ni2MoV steel. Eng Fract Mech 2015; 144: 1-15.

[34] Oliver WC, Pharr GM. Measurement of hardness and elastic modulus by instrumented indentation: Advances in understanding and refinements to methodology. J Mater Res 2004; 19: 3-20.

[35] Kang JJ, Becker AA, Sun W. Determining elastic-plastic properties from indentation data obtained from finite element simulations and experimental results. 
Int J Mech Sci 2012; 62: 34-46.

[36] ASTM E466-2007. Conducting Force Controlled Constant Amplitude Axial Fatigue Tests. American Society for Testing Materials, 2007.

[37] Kang GZ, Liu YJ. Uniaxial ratchetting and low-cycle fatigue failure of the steel with cyclic stabilizing or softening feature. Mater Sci Eng A 2008; 472: 258-68.

[38] Shan HX. Low cycle fatigue stress-strain relation model of cyclic hardening or cyclic softening materials. Eng Fract Mech 1996; 54: 1-9.

[39] Nagesha A, Valsan M, Kannan R, Rao KBS, Mannan SL. Influence of temperature on the low cycle fatigue behavior of a modified $9 \mathrm{Cr}-1 \mathrm{Mo}$ ferritic steel. Int J Fatigue; 2002, 24: 1258-93.

[40] Fournier B, Sauzay M, Caës C, Noblecourt M, Mottot M. Analysis of the hysteresis loops of a martensitic steel part I: study of the influence of strain amplitude and temperature under pure fatigue loadings using an enhanced stress partitioning method. Mater Sci Eng A 2006; 437: 183-96.

[41] Guguloth K, Sivaprasad S, Chakrabarti D, Tarafder S. Low-cyclic fatigue behavior of modified 9Cr-1Mo steel at elevated temperature. Mater Sci Eng A 2014; 604: 196-206.

[42] Wu DL, Xuan FZ, Guo SJ, Zhao P. Uniaxial mean stress relaxation of 9-12\% Cr steel at high temperature: Experiments and viscoplastic constitutive modeling. Int J Plasticity 2016; 77: 156-73.

[43] Hao H, Ye DY, Chen YZ, Mi F, Li JZ. A study on the mean stress relaxation behavior of 2124-T851 aluminum alloy during low-cycle fatigue at different strain ratios. Materials and Design 2015; 67 : 272-9.

[44] Furuya Y, Abe T. Effect of mean stress on fatigue properties of $1800 \mathrm{MPa}$-class spring steels. Mater Des 2011; 32:1101-7.

[45] Kamaya M, Kawakubo M. Mean stress effect on fatigue strength of stainless steel. Int J Fatigue 2015; 74:20-9.

[46] Socie DF, Morrow J. Review of contemporary approaches to fatigue damage analysis. In: Risk and failure analysis for improved performance and reliability. New York (NY): Plenum Pub Corp; 1980:141-94. 
[47] Smith K, Watson P, Topper T. Stress-strain function for the fatigue of metals. J Mater 1970; 5(4):767-78.

[48] Plumtree A, Abdel-Raouf H. Cyclic stress-strain response and substructure. Int J Fatigue 2001; 23: 799-805

[49] Abdel-Raouf H, Topper TH, Plumtree A. Cyclic plasticity and Masing behavior in metals and alloys. In: Proceedings of the 4th international conference on fracture. Waterloo: Pergamon Press, 1977; 1207-15.

[50] Yaguchi M, Takahashi Y. Ratchetting of viscoplastic material with cyclic softening, part 1: experiments on modified 9Cr-1Mo steel. Int J Plasticity 2005; 21: 43-65.

[51] Zhu ML, Wang DQ, Xuan FZ. Effect of long-term aging on microstructure and local behavior in the heat-affected zone of a $\mathrm{Ni}-\mathrm{Cr}-\mathrm{Mo}-\mathrm{V}$ steel welded joint. Mater Charact 2014; 87: 45-61.

[52] Jen YM, Chang LY, Fang CF. Assessing the fatigue life of butt-welded joints under oblique loading by using local approaches. Int J Fatigue 2008; 30: 603-13. 


\section{List of Figure captions}

Figure 1 Schematic diagram of the welded joint and locations of the specimens.

Figure 2 Sketch for the locations of the Nano-identation tests and the micro-tensile specimen.

Figure 3 The microstructures in the different regions of the welded joint: (a) base metal (BM); (b) heat affected zone (HAZ); (c) weld metal (WM)

Figure 4 The geometry of specimens for cyclic loading tests: (a) base metal(BM); (b) weld metal (WM).

Figure 5 The finite element meshes of the WM specimen.

Figure 6 The local mechanical distribution of the welded joint: (a) the hardness; (b) the yield stress

Figure 7 Evolution curve of stress amplitudes in the strain-controlled fatigue tests for WM and BM.

Figure 8 The schematic diagram of transient softening factors $(S F)$ and instantaneous softening speed $\frac{\mathbb{R}}{\mathrm{a}}$.

Figure 9 Evolution curve of SF with fatigue life for the strain-controlled fatigue tests:

(a) weld metal (WM); (b) base metal (BM).

Figure 10 The instantaneous softening speed of for the WM and BM at different fatigue life stage and varying strain amplitudes.

Figure 11 The mean stress relaxation behavior of WM and BM at different applied strain amplitude.

Figure 12 The hysteresis loops at the half-life cycle and the corresponding cyclic stress-strain curves (a) weld metal (WM); (b) base metal (BM).

Figure 13 The hysteresis loops from different life periods (a) weld metal (WM); (b) base metal (BM)

Figure 14 The ratchetting strain evolution curves: (a) weld metal (WM); (b) weld metal (WM) and base metal (BM).

Figure 15 Microstructure and inclusion morphology in the BM and WM: (a) the as-received $\mathrm{BM}$; (b) the as-received $\mathrm{WM}$; (c) inclusion in the BM; (d) 
inclusion in the WM

Figure 16 The evolution of stress-strain hysteresis loops of WM and BM.

Figure 17 The evolution curve of strain amplitudes of WM and BM.

Figure 18 The relationship between average ratchetting strain rate and stress ratio $\mathrm{R}$ for WM.

Figure 19 Strain amplitude vs. number of reversals to failure for the WM and BM.

Figure 20 Failure behavior and failure location observation and statistics for the WM specimens.

Figure 21 The equivalent plastic strain amplitude distribution contours for the WM specimens at various applied strain amplitudes.

Figure 22 The equivalent plastic strain amplitude distribution along dinger line in the WM specimens at various applied strain amplitudes 


\section{List of Table captions}

Table 1 Detail of all the loading conditions.

Table 2 Cyclic stress-strain parameters for the WM and BM. 